\title{
Revisão das espécies brasileiras do gênero Exoplectra Chevrolat (Coleoptera, Coccinellidae, Exoplectrinae, Exoplectrini) ${ }^{1}$
}

\author{
Ana V. Costa², Lúcia M. Almeida ${ }^{2,3}$ \& Geovan H. Corrêa ${ }^{2,3}$
}

${ }^{1}$ Contribuição número 1640 do Departamento de Zoologia, UFPR.

${ }^{2}$ Departamento de Zoologia, Universidade Federal do Paraná, Caixa Postal 19030, 81531-980 Curitiba-PR, Brasil. aviecst@yahoo.com.br; lalmeida@ufpr.br; geovanbiologo@yahoo.com.br

${ }^{3}$ Bolsistas do $\mathrm{CNPq}$

\begin{abstract}
A revision of Brazilian species of the genus Exoplectra Chevrolat (Coleoptera, Coccinellidae, Exoplectrinae, Exoplectrini). The Brazilian species of Exoplectra Chevrolat, 1844, based on the morphological analysis of external characters and genitalia, are revised. Among the 37 species in the genera, 14 Brazilian species were analysed, including three new species. It was studied the type material of nine of them. The lectotypes of E. angustifrons Weise, 1895, E. calcarata (Germar, 1824), E. coccinea (Fabricius, 1801) and E. miniata (Germar, 1824) are designated. Exoplectra companyoi Mulsant, 1850 is revalidated; E. aenea (Fabricius, 1801), E. bernardinensis Brèthes, 1925, E. impotens Mulsant, 1850, E. luteicornis Mulsant, 1850 and E. irregularis (Crotch, 1874) are provisionally removed from the genus. Two new species from Brazil are proposed: E. columba sp. nov., from Paraná and E. bimaculata sp. nov., from Amazonas. Dicotomic key for species is presented as well as pictures and illustrations for the main structures used in the identification.
\end{abstract}

KEYWORDS. Morphology; Neotropical; taxonomy.

\begin{abstract}
RESUMO. Revisão das espécies brasileiras do gênero Exoplectra Chevrolat (Coleoptera, Coccinellidae, Exoplectrinae, Exoplectrini). As espécies brasileiras de Exoplectra Chevrolat, 1844 são revisadas com base no estudo de caracteres morfológicos do exoesqueleto e genitália. Dentre as 37 espécies do gênero foram estudadas 14 brasileiras, incluindo as três propostas como novas. Foi examinado o material-tipo de nove espécies. São designados os lectótipos de $E$. angustifrons Weise, 1895, E. calcarata (Germar, 1824), E. coccinea (Fabricius, 1801) e E. miniata (Germar, 1824). Exoplectra companyoi Mulsant, 1850 é revalidada; E. aenea (Fabricius, 1801), E. bernardinensis Brèthes, 1925, E. impotens Mulsant, 1850, E. luteicornis Mulsant, 1850 e E. irregularis (Crotch, 1874) são provisoriamente removidas do gênero. São propostas duas novas espécies do Brasil: E. columba sp. nov., do Paraná e E. bimaculata sp. nov., do Amamzonas. É apresentada chave dicotômica para as espécies, fotos e desenhos das principais estruturas utilizadas para identificação.
\end{abstract}

PALAVRAS-CHAVE. Morfologia; Neotropical; taxonomia.

O gênero Exoplectra Chevrolat, 1844 teve a maioria das espécies descritas por Mulsant em 1850, dentre as quais, oito brasileiras. Crotch (1874) descreveu cinco espécies para o Brasil, uma de Caiena e sinonimizou seis espécies de Mulsant. Posteriormente Weise (1895) descreveu três novas espécies, duas do Paraguai e uma da região Amazônica. Bruch (1914) relacionou em seu catálogo sistemático, Exoplectra fulgurata Berg, 1874 e E. funebris Weise, 1895, de ocorrência na Argentina. Brèthes (1925) descreveu E. bernardinensis, do Paraguai e citou E. miniata do Rio de Janeiro, Brasil. Korschefsky (1932) e Blackwelder (1945) citaram 30 espécies para o gênero Exoplectra, 15 brasileiras.

Ao revisar os Coccinellidae da América do Norte, Gordon (1985) indicou Exoplectra como o único gênero neotropical da tribo Exoplectrini. No mesmo trabalho redescreveu brevemente o gênero e descreveu uma espécie nova do México. Referiu-se às mandíbulas com fortes dentes como evidência para indicar o hábito predador de Exoplectra e de outros gêneros da tribo, registrando como presa Aleurodicus cocois (Curtis, 1846) (Hemiptera, Aleyrodidae).

Em 1980 foram identificadas por Bartoszeck, larvas e adultos de algumas espécies de Coccinellidae incluindo Exoplectra, todas predando Toxoptera citricidus (Kirkaldy, 1907) (Hemiptera, Aphididae) em Citrus limon Burmann e Citrus sinensis Osbeck (Rutaceae) na chácara Estância do Sol, Imperatriz, Maranhão.

Em 1990 Drea \& Gordon indicaram Aspidiotus (Hemiptera, Diaspididae) como presa para Exoplectra dubia Crotch, 1874.

O gênero Exoplectra e as seguintes espécies são aqui redescritas; Exoplectra amazonica Crotch, 1874; Exoplectra angustifrons Weise, 1895; Exoplectra batesii Crotch, 1874; Exoplectra brasiliensis Nunenmacher, 1912; Exoplectra calcarata (Germar, 1824); Exoplectra coccinea (Fabricius, 1801); Exoplectra companyoi Mulsant, 1850, aqui revalidada; Exoplectra dubia Crotch, 1874; 1850; Exoplectra heydeni Mulsant, 1850; Exoplectra metallescens Mulsant, 1850; Exoplectra miniata (Germar, 1824) e Exoplectra santaremae Crotch, 1874. São descritas como novas as espécies: Exoplectra columba sp. nov. e Exoplectra bimaculata $\mathbf{s p . ~ n o v . . ~}$

\section{MATERIALE MÉTODOS}

O material examinado pertence às seguintes intituições: Department of Zoology, University of Cambridge, Cambridge, 
Inglaterra (DZUC); Coleção de Entomologia Pe. J. S. Moure, Departamento de Zoologia, Universidade Federal do Paraná, Curitiba, Brasil (DZUP); Museu Nacional da Universidade Federal do Rio de Janeiro, Rio de Janeiro, Brasil (MNRJ); Museu de Zoologia, Universidade de São Paulo, São Paulo, Brasil (MZSP); Museum für Naturkunde der Humboldt-Universität zü Berlim, Berlim, Alemanha (MNHUB); Museu de História Natural Capão da Imbuia, Curitiba, Paraná, Brasil (MNCI); Instituto Nacional de Pesquisas da Amazônia, Manaus, Brasil (INPA); Coleção Entomológica Adolph Hempel São Paulo, Instituto Biológico, São Paulo, Brasil (IBSP); United States National Museum, Washington, D. C., Estados Unidos (USNM); Fundação Zoobotânica do Rio Grande do Sul, Porto Alegre, Brasil (FZRG), California Academy of Sciences, San Francisco, Estados Unidos (CAS), Zoological Museum, University of Copenhagen, Dinamarca (ZMUC).

A terminologia adotada seguiu Marinoni \& Almeida (1983), Almeida (1987) e Almeida \& Milléo (2000).

\section{RESULTADOS EDISCUSSÃO}

\section{Exoplectra Chevrolat, 1844}

Espécie tipo: Coccinella coccinea Fabricius, 1801

Exoplectra Chevrolat, 1844: 545; Mulsant, 1850: 908, 916 - 927 e 1042; Berg, 1874: 292; Crotch, 1874: 284; Chapuis, 1876: 238, 241; Gemminger \& Harold, 1876: 3081; Gorhan, 1895: 213; Weise, 1895: 130; Casey, 1908: 407; Nunenmacher, 1912:151; Sicard, 1912: 137; Bruch, 1914: 389; Weise, 1922: 37; Brèthes, 1925: 8; Korschefsky, 1932: 227; Blackwelder, 1945: 450; Contreras, 1951: 244; Gordon, 1985: 670; Gordon, 1987: 34; Chazeau et al. 1989: 6-8; Drea \& Gordon, 1990: 37; Fürsch, 1990: 4,11; Gordon, 1994: 682.

Macho. Corpo arredondado ou ovalado, convexo, apresentando pubescência uniforme, curta e adensada de coloração branca a amarelada (Figs. 1, 2 e 63). Tegumento alaranjado a avermelhado ou preto metálico com reflexo verde, azul, bronze ou rubro, com ou sem máculas. Superfície ventral avermelhada, castanha ou preta.

Cabeça de coloração castanha, avermelhada ou preta, subquadrada, com largura cerca de 1,2 vezes o comprimento. Clípeo fundido à fronte, sem sutura fronto-clipeal, expandido lateralmente e com bordas anteriores arredondadas. Olhos divididos pela gena, pubescentes e encobertos apicalmente pelo pronoto (Figs. 3, 4 e 64). Labro transverso, com bordas arredondadas (Fig. 5). Mandíbulas assimétricas, robustas, com ápice denteado, mola direita com dente afilado e a esquerda com dente subquadrado (Fig. 6). Maxilas com o último artículo do palpo distintamente securiforme (Fig. 7). Lábio alongado, lígula com cerdas curtas até a metade látero-apical e algumas longas centrais, mento lateralmente projetado, com bordas arredondadas e com cerdas longas (Fig. 8). Antena clavada com onze artículos, clava formada pelos artículos 8 a 11, este último tão longo quanto largo e escapo distintamente dilatado (Figs. 9, 65 e 66).

Pronoto tranverso com borda anterior escavada em volta da cabeça, com mácula castanha, avermelhada, alaranjada ou translúcida contornando a margem apical e as laterais (Fig. 3). Processo prosternal arredondado com duas carenas subparalelas nas bordas laterais contornando-o internamente (Figs. 10, 67 e 68). Proendosternito com braços longos e afilados (Fig. 11). Metendosternito trapezoidal com borda anterior arredondada, tendões anteriores alongados e braços laterais da furca tão longos quanto o comprimento da haste (Fig. 12). Escutelo pequeno e triangular.

Élitros com margem anterior truncada, com ou sem máculas, estas variando na forma, número e posição (Figs. 13 e 69), epipleura larga e pouco inclinada sem escavação para recepção dos fêmures (Fig. 70); asas membranosas com lobo anal arredondado, veia Costa (C) curta, pouco evidente; Subcosta (Sc) subparalela a margem anterior da asa, freqüentemente estendendo-se até cerca de 1/3 do comprimento da asa; Radial (R) desenvolvida e larga na região mediana da asa; Cubital $(\mathrm{Cu})$ longa dirigindo-se à margem inferior da asa e na metade apical formando uma célula aberta com a Mediana (M); Anais (A) formando uma célula na metade basal; Plical (P) pouco visível e Empusal (E) voltada para a Cubital (Cu) (Fig. 14). Fêmures relativamente largos, escavados para recepção das tíbias, estas com grande dente externo arredondado ou agudo em forma de espinho, escavada para recepção dos tarsos (Figs. $15,16,17,71,72$ e 73). Pernas médias e posteriores com dois esporões apicais na tíbia (Figs. 16, 17 e 75). Garras tarsais com dente (Fig. 74). Abdome com cinco segmentos, com linha póscoxal incompleta, tocando ou não a sutura entre o primeiro e segundo esternos abdominais visíveis (Figs. 18, 76 e 77), linha oblíqua presente (Fig. 78) ou não.

Genitália. Lobo médio simétrico, largo na base e afilando gradativamente até o ápice, podendo ser mamiliforme ou arredondado, parâmeros largos e mais longos que o lobo médio, com cerdas curtas ou longas (Fig. 19). Sifão esclerotizado com ápice arredondado, com bolsa prepucial desenvolvida ou não e cápsula sifonal alongada (Fig. 20).

Fêmea. Sem dimorfismo sexual.

Genitália. Coxitos cerca de três vezes mais longos que largos ou subtriangulares. Espermateca em forma de "C", com ramo e nódulo distintos, sem infundíbulo, com glândula acessória evidente e ducto da espermateca longo, afilado e esclerotinizado. Estilo mamiliforme com cerdas longas (Fig. 21).

Dimensões (em mm). Comprimento total: 3,00 - 7,30. Largura total: $2,50-5,75$.

Discussão taxonômica. Mulsant (1850) em seu trabalho "Species des Coléoptères Trimères Sécuripalpes" criou um novo gênero denominado Coeliaria para abrigar espécies de Exoplectra que apresentavam fossetas torácicas como as encontradas em Exoplectra erithrogaster. Em 1874, Crotch transferiu E. eritrogaster para Coeliaria e explicou que este gênero difere de Exoplectra pela presença de fóveas torácicas. Chapuis (1876) indicou que Coeliaria poderia formar um subgênero, por apresentar essas fóveas torácicas, enquanto que em Exoplectra a epipleura é plana. Neste mesmo trabalho 
discutiu as semelhanças e diferenças entre Exoplectra e Azya Mulsant, 1850.

Gorhan (1895) também comparou estes dois gêneros e distinguiu algumas espécies pela coloração vermelha com máculas nos élitros, tíbias denteadas e garras bifidas. Comentou ainda sobre o dente da tíbia, diferente do encontrado em Azya, qu é largo, angular e com dilatação na base e sobre a epipleura do élitro com margem interna profundamente dividida, como em Chilocorus Leach, 1815, do qual Exoplectra parecia ser próximo.

Exoplectra difere de Chnoodes Chevrolat, 1837, principalmente pela presença de dente lateral bastante evidente na tíbia, de Coeliaria erithrogaster Mulsant, 1850, única espécie do gênero, pela fosseta torácica e também pelo dente na tíbia. Quanto à $A z y a$ a única semelhança é a presença de dente na tíbia, porém este gênero apresenta outras características bastante distintas, pois pertence à subfamília Azyinae (Gordon 1994).

De Chilocorus difere principalmente por não apresentar expansão lateral do clípeo e pela ausência das fóveas torácicas.

Chave de identificação para as espécies de Exoplectra do Brasil

1). Tegumento preto metálico a castanho com reflexo de cores variadas

Tegumento avermelhado, sem reflexo .............................. 7

2). Coloração preta com reflexo azul ou bronze .................... 3

Coloração preta com reflexo verde ...................................... 4

3). Coloração preta metálica com reflexo azulado, pubescência branca; pronoto com borda látero apical castanha; pernas castanhas, tíbias com dente agudo; abdome avermelhado, sem linha oblíqua (Fig. 51) .......

E. batesii Crotch, 1874

Coloração preta metálica com reflexo bronze, pubescência amarelada; pronoto com borda láteroapical translúcida; pernas pretas; abdome com o primeiro segmento preto e demais avermelhados, com linha oblíqua (Fig. 56)

E. dubia Crotch, 1874

4). Com corpo ovalado; superfície ventral avermelhada, dente da tíbia obtuso, tarsos castanhos (Fig. 61) .....

E. columba sp.nov.

Corpo arredondado e outro conjunto de caracteres ..... 5

5). Pubescência branca, primeiro segmento abdominal de coloração preta com linha oblíqua, os demais avermelhados; comprimento de 5,75 mm e largura de 5,0 mm (Fig. 53) E. calcarata (Germar, 1824)

Outro conjunto de caracteres ... 6

6). Comprimento e largura, em média, 5,62 e 5,17 mm, pronoto com borda látero apical castanha (Fig. 55) ...........

E. companyoi Mulsant, 1850 sp. rev.
Comprimento e largura, em média, 6,95 e 6,22 mm, coloração preta com pronoto com borda látero apical avermelhada (Fig. 57) .. E. metallescens Mulsant, 1850

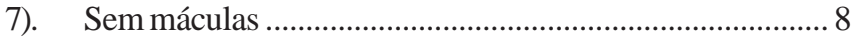

Com uma ou mais máculas em cada élitro ..................... 11

8). Coloração vermelho intenso, comprimento $5,67 \mathrm{~mm}$, fêmures pretos, tíbias com dente agudo, abdome sem linha oblíqua (Fig. 58) ....... E. heydeni Mulsant, 1850

Coloração variando do vermelho amarelado escuro a alaranjado

9). Tamanho $3,0 \mathrm{~mm}$, pronoto com contorno látero-apical translúcido, tíbias com dente agudo, abdome sem linha oblíqua (Fig. 50) .... E. angustifrons Weise, 1895

Outra combinação de caracteres 10

10). Coloração geral alaranjada, pronoto com contorno láteroapical translúcido, tíbias com dente obtuso, abdome com linha blíqua (Fig. 54)

E. coccinea (Fabricius, 1801)

Coloração geral vermelho amarelado, pronoto e élitros nas bordas com reflexo mais escuro, pubescência branca (Fig. 52)

E. brasiliensis Nunenmacher, 1912

11). Cada élitro com uma mácula semicircular junto à linha de sutura formando um grande círculo preto, pronoto preto com borda larga látero-anterior alaranjada, coloração torácica preta com as margens laterais avermelhadas, pernas pretas e tíbias castanhas com dente agudo, abdome avermelhado com linha oblíqua (Fig. 49) ………………..... E. amazonica Crotch, 1874

Cada élitro com mais de uma mácula .............................. 12

12). Cada élitro com duas máculas circulares pretas, uma central junto à sutura e a outra central junto à margem externa, coloração torácica e das pernas enegrecidas com dente agudo, abdome com o primeiro segmento enegrecido, e os demais avermelhados, com linha oblíqua (Fig. 62)

E. bimaculata sp. nov.

Cada élitro com mais de duas máculas, pronoto preto, com borda látero apical alaranjada ou com duas máculas pretas ... 13

13). Cada élitro com três máculas pretas, uma semicircular central grande formando um círculo, outra circular próxima ao calo umeral e a última em faixa larga sinuosa contornando toda a margem externa até o ápice onde se alarga, pernas escuras (Fig. 60)

E. santaremae Crotch, 1874

Cada élitro com cinco máculas circulares pretas, pronoto com duas máculas circulares pretas, fêmures pretos e tíbias com dente obtuso, avermelhadas, abdome com linha oblíqua (Fig. 59) ........E. miniata (Germar, 1824) 
Exoplectra amazonica Crotch, 1874

(Figs. 22 - 24, 49)

Exoplectra amazonica Crotch, 1874: 286; Korschefsky, 1932: 227; Blackwelder, 1945: 450; Gordon, 1987: 34.

Macho. Corpo arredondado (Fig. 49), pubescência branca. Cabeça preta, labro com a margem externa, submento e antenas castanhos, demais peças enegrecidas. Pronoto preto, com borda látero-anterior alaranjada contornando finamente a margem apical e estendendo-se lateralmente. Escutelo preto. Élitros avermelhados, cada um com uma mácula no centro, semicircular, junto à linha de sutura, formando no centro do corpo uma mácula circular. Meso e metaesterno pretos no centro com as margens laterais avermelhadas. Epipleura avermelhada com contorno externo preto. Fêmures pretos e tíbias castanhas, com dente lateral agudo, em forma de espinho. Abdome avermelhado, com linha oblíqua.

Genitália. Parâmeros largos, com cerdas longas, pouco maiores que o lobo médio, este mamiliforme (Fig. 22). Sifão longo com cápsula sifonal alongada e ápice arredondado (Fig. 23).

Fêmea. Semelhante ao macho.

Genitália. Coxitos três vezes mais longos que largos. Espermateca com o ramo pouco mais curto que o nódulo (Fig. 24).

Dimensões (em mm). Comprimento total: 4,75. Largura: 4,17.

Distribuição geográfica. Brasil (Amazonas).

Discussão taxonômica. Exoplectra amazonica assemelhase a E. miniata, E. santaremae e E. bimaculata sp. nov., por apresentar corpo arredondado, tegumento avermelhado, pubescência branca e abdome com linha oblíqua. O dente lateral da tíbia é agudo e em forma de espinho como em $E$. santaremae e em E. bimaculata sp. nov.

Difere das mesmas pela presença de uma única mácula no centro de cada élitro, semi-circular, junto à linha de sutura e pelo padrão da genitália do macho.

Material-tipo. O holótipo o estudado pertence ao Departament of Zoology, University of Cambridge, Cambridge, Inglaterra e possui as seguintes etiquetas: uma azul: [HOLOTYPE, Exoplectra amazonica Crotch, 1874] e duas brancas: [TYPE, amazonica, Ega] e [University Museum of Zoology, CAMBRIDGE].

Material examinado. BRASIL. Amazonas. Ega (atual Tefé), sem data, 1 espécime o holótipo (DZUC); 13.I.1956, sem coletor, 4 espécimes (MNRJ).

\section{Exoplectra angustifrons Weise, 1895}

(Figs. 25 - 27, 50)

Exoplectra angustifrons Weise, 1895: 131; Korschefsky, 1932: 227; Blackwelder, 1945: 450.

Macho. Corpo arredondado (Fig. 50), pubescência branca. Tegumento vermelho, sem máculas. Cabeça castanha, peças bucais e antenas amareladas. Pronoto com contorno látero- apical translúcido. Coloração ventral do tórax amarelada. Pernas alaranjadas, tíbia com dente lateral agudo em forma de espinho. Abdome avermelhado, sem linha oblíqua.

Genitália. Lobo médio estreito com ápice ligeiramente arredondado, pouco mais curto que os parâmeros, estes com cerdas longas distribuídas em toda superfície (Fig. 25). Sifão com a cápsula curta e o ápice arredondado envolto por uma membrana (Fig. 26).

Fêmea. Semelhante ao macho.

Genitália. Coxitos pequenos e subtriangulares. Espermateca com ramo pouco mais curto que o nódulo (Fig. 27).

Dimensões (em mm). Comprimento total: 2,83 -3,00. Largura: $2,50-2,83$.

Distribuição geográfica. Brasil (Amazonas, Pará).

Discussão taxonômica. Exoplectra angustifrons difere das demais espécies do gênero pelo seu tamanho menor e pelo padrão de coloração uniforme avermelhado sem máculas. Assemelha-se a E. brasiliensis pelo tamanho, porém distinguese por possuir coloração avermelhada, enquanto que em $E$. brasiliensis a coloração é vermelha alaranjada. Difere também pelo padrão de genitália do macho e da fêmea.

Material-tipo. Dentre o material enviado pelo Museum für Naturkunde der Humboldt-Universitat zü Berlim, Berlim, Alemanha, havia um único exemplar indicado como síntipo com as seguintes etiquetas: duas brancas: [Itaituba] e [Exoplectra angustifrons] e uma vermelha [Syntypus, Exoplectra angustifrons Weise, 1895, labeled by MNHUB 2005]. Este exemplar é designado aqui como lectótipo.

Material examinado. BRASIL. Amazonas. Manaus, Fazenda Esteio, ZF - 3 km 23, 02.IV.1985, 1 espécime; 3.IV.1985, 1 espécime; 17.IV.1985, 3 espécimes; 18.04.1985, 1 espécime o ; 29.V.1986, 1 espécime; 13.VIII.1986, 1 espécime, B.C.Klein col. (INPA); Itacoatiara, II. 1964, Dirings, 4 espécimes (MZSP). Pará. Itaituba, sem data, sem coletor, lectótipo (MNHUB). Santarém, sem data e coletor, Dieke, 1954 det., Coleção G. H. Dieke, 1965, 2 espécimes (USNM); Marabitanas (atual São Caetano de Odivelas), VII.1949, J. C. M. Carvalho Col., 1 espécime (INPA); Óbidos (Traíra), IV.1962, Dirings, 1 espécime (MZSP).

\section{Exoplectra batesii Crotch, 1874}

(Figs. 28 - 29, 51)

Exoplectra batesii Crotch, 1874: 284; Korschefsky, 1932: 227; Blackwelder, 1945: 450; Gordon, 1987: 34.

Macho. Corpo oval (Fig. 51), pubescência branca. Tegumento preto metálico, com reflexo azulado. Cabeça preta, com a margem externa do clípeo, peças bucais e antenas castanhas. Pronoto com borda látero-apical castanha. Coloração ventral castanho avermelhada. Pernas castanhas, tíbias com dente lateral agudo em forma de espinho. Abdome castanho avermelhado, sem linha oblíqua.

Genitália. Parâmeros largos, com cerdas finas e curtas, distribuídas em toda superfície pouco mais longo que lobo médio, este mamiliforme no ápice (Fig. 28). Sifão com cápsula alongada e ápice envolto por membrana (Fig. 29).

Dimensões (em mm). Comprimento total: 4,83 - 5,75. Largura: 4,17-5,00. 


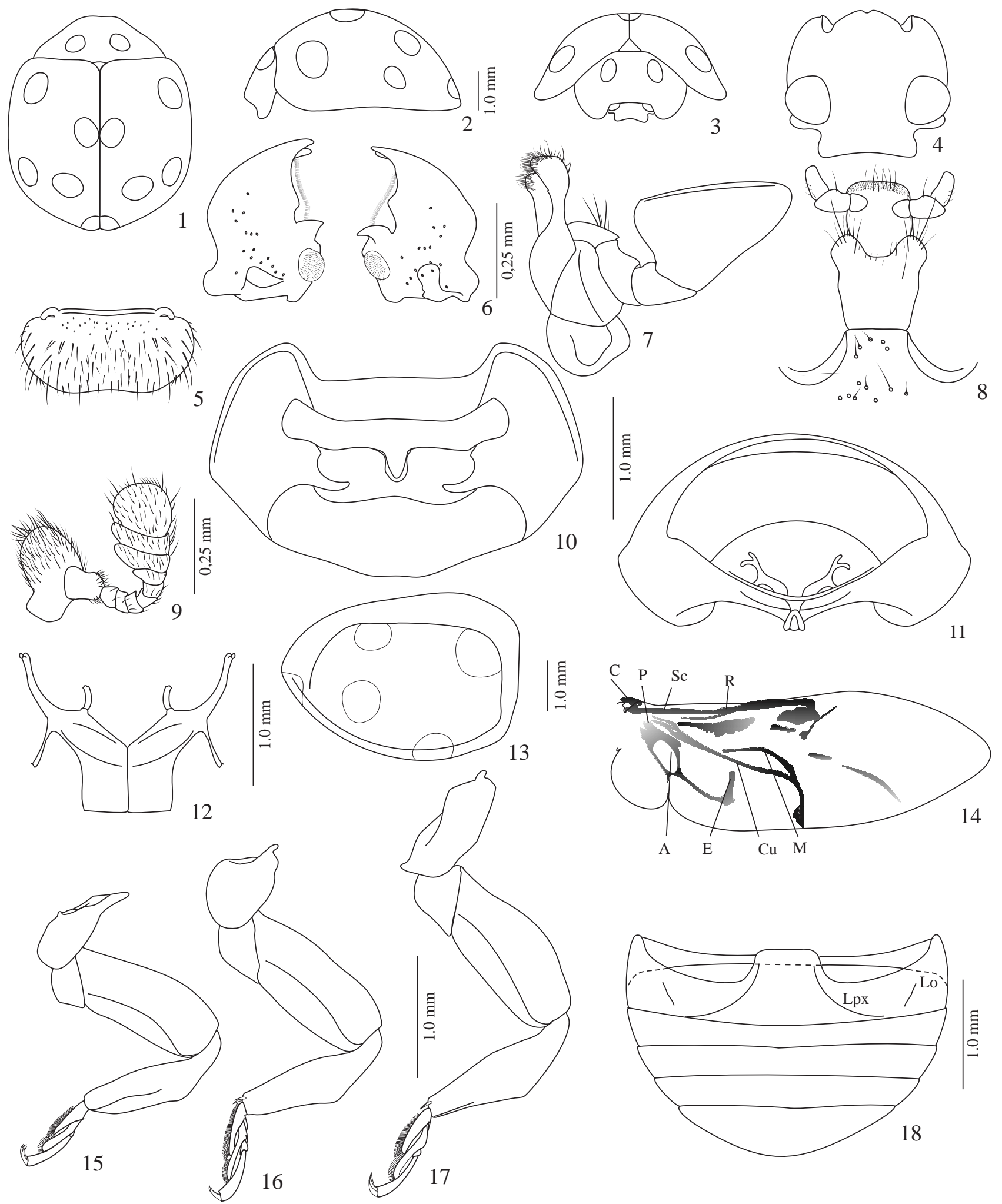

Figs. 1-18. Exoplectra miniata (Germar, 1824). 1, vista dorsal; 2, vista lateral; 3, vista frontal; 4, cabeça, vista frontal; 5, labro; 6, mandíbulas; 7, maxila; 8, lábio; 9, antena; 10, protórax ventral; 11, proendosternito; 12, metendosternito; 13, élitro, vista ventral; 14, asa; 15, perna anterior; 16, perna média; 17, perna posterior; 18, abdome, vista ventral. Lo = linha oblíqua; Lpx = linha pós-coxal. 


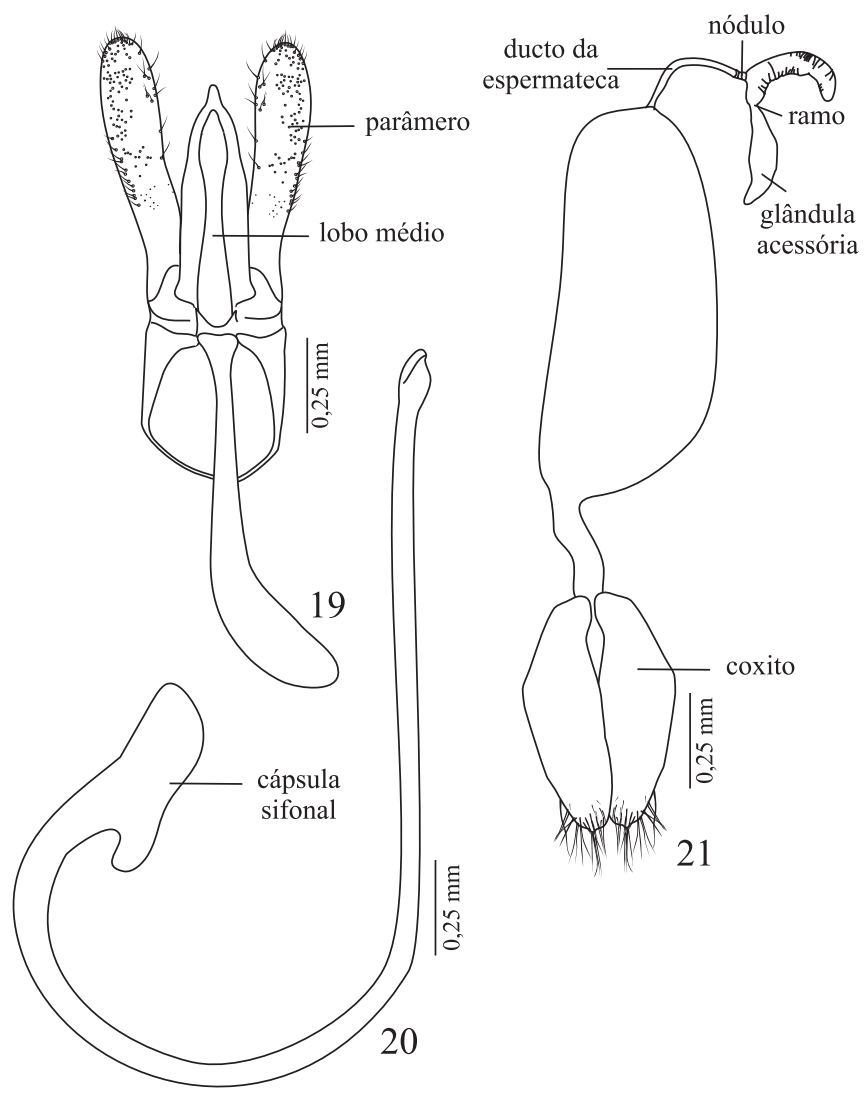

Figs. 19-21. Exoplectra miniata (Germar, 1824). Genitália do macho; 19, tégmen; 20, sifão; 21, genitália da fêmea.

Distribuição geográfica. Brasil (Amazonas).

Material-tipo. O holótipó ơ estudado pertence ao Departament of Zoology, University of Cambridge, Cambridge, Inglaterra e possui as seguintes etiquetas: duas azuis: [TYPE] e [HOLOTYPE, Exoplectra batesii Crotch, 1874] e duas brancas: [TYPE, batesii, Ega] e [University Museum of Zoology, CAMBRIDGE].

Material examinado. BRASIL. Amazonas. Ega (atual Tefé), sem data, sem coletor, 1 espécime $\sigma^{\pi}$ holótipo (DZUC).

Discussão taxonômica. Exoplectra batesii compartilha com E. dubia a forma do corpo oval e a pubescência branca. Embora as duas espécies apresentem coloração preta, E. batesii diferencia-se pelo reflexo azul, enquanto que E. dubia possui tons avermelhados, além da ausência de linha oblíqua e diferente coloração das pernas.

Exoplectra brasiliensis Nunenmacher, 1912 (Figs. 30 - 32, 52)

Exoplectra brasiliensis Nunenmacher, 1912: 151; Korschefsky, 1932: 227; Blackwelder, 1945: 450.

Macho. Corpo arredondado (Fig. 52), pubescência branca. Tegumento vermelho alaranjado, sem máculas, com reflexo nas bordas do pronoto e élitros mais escuros. Pronoto com bordas laterais alaranjadas. Coloração ventral e das pernas avermelhada, tíbias com dente lateral agudo. Abdome vermelho, sem linha oblíqua.

Genitália. Lobo médio largo com ápice mamiliforme e com cerdas apicais, pouco mais curto que os parâmeros, estes largos, com cerdas longas distribuídas em toda superfície (Fig. 30). Sifão com a cápsula curta e o ápice arredondado com algumas cerdas (Fig. 31).

Fêmea. Semelhante ao macho.

Genitália. Coxitos alongados, três vezes mais longos que largos e subtriangulares. Espermateca com ramo mais curto que o nódulo (Fig. 32).

Dimensões (em mm). Comprimento total: 3,10. Largura: 2,50.

\section{Distribuição geográfica. Brasil (Amazonas).}

Material-tipo. O holótipo foi recebido da California Academy of Sciences, São Francisco, Estados Unidos, com as seguintes etiquetas: quatro brancas: [\%], [Exoplectra brasiliensis Nun.], [Mann \& Baker Rio Madeira Brasil] e [California Academy of Sciences Type No. 5727] e uma vermelha [TYPE]

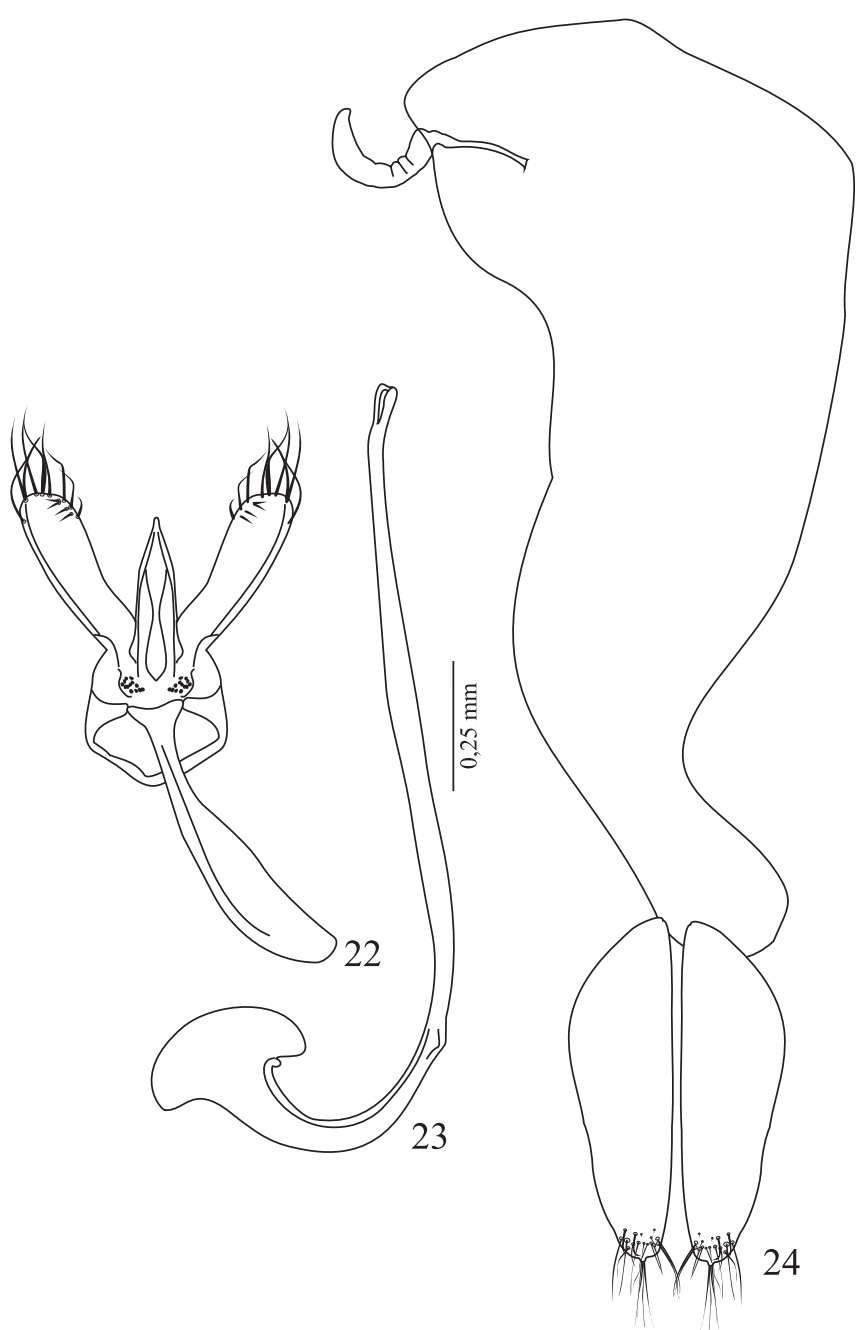

Figs. 22-24. Exoplectra amazonica Crotch, 1874. Genitália do macho: 22, tégmen; 23, sifão; 24, genitália da fêmea. 


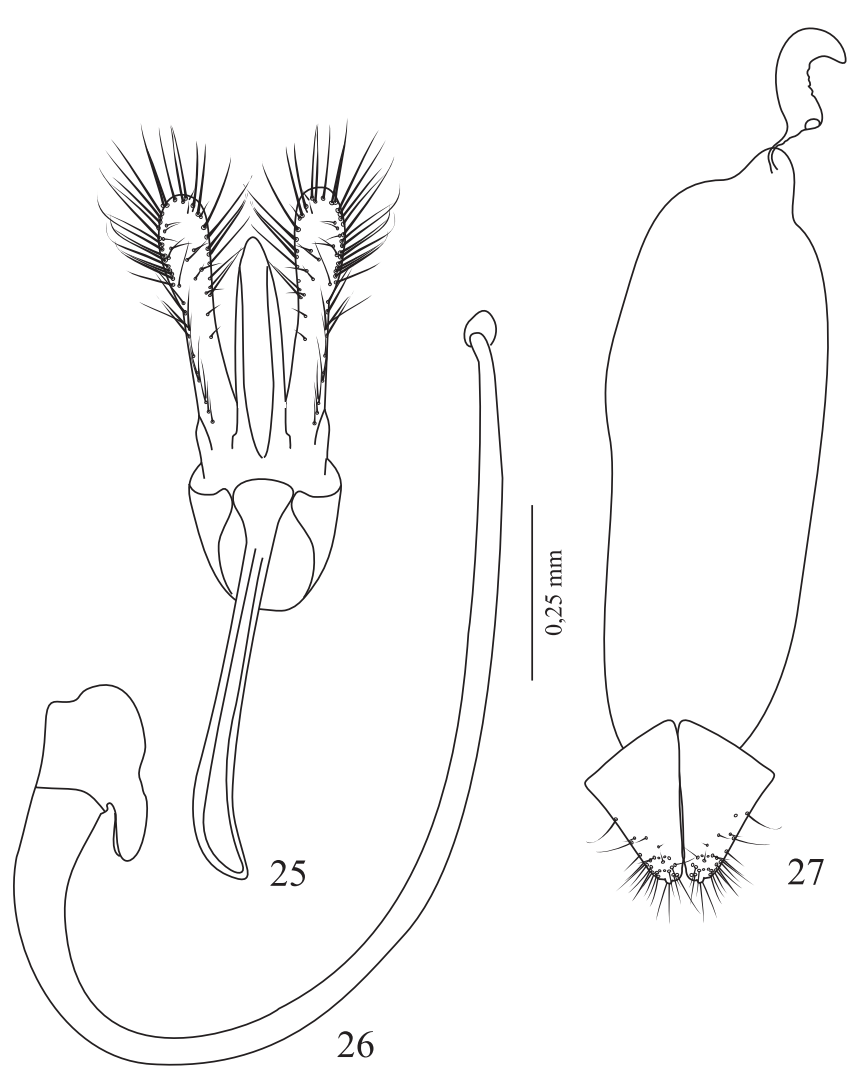

Figs. 25-27. Exoplectra angustifrons Weise, 1895. Genitália do macho: 25, tégmen; 26, sifão; 27, genitália da fêmea.

Material examinado. BRASIL. Amazonas. Rio Madeira, sem data, Mann \& Baker, holótipo (CAS). Manaus, Reserva Campinas, $60 \mathrm{Km}$ N, 14.I.1977, B.C. Ratcliffe, 1 exemplar; Reserva Ducke, Am 010. Km. 26, 14.II.1978, Jorge Arias col., malaise trap, 1 exemplar; Manaus, $60 \mathrm{Km} \mathrm{N}$, Fazenda Esteio, ZF-3 Km-23, 18.IV.1985, B. C. Klein (malaise) Reserva 1210, 1 exemplar (INPA).

Discussão taxonômica. Exoplectra brasiliensis assemelhase a E. angustifrons pelo tamanho e a E. coccinea pela coloração uniforme, sem máculas. Difere das espécies do gênero pela coloração vermelho-alaranjada sem máculas e pelo padrão da genitália do macho e da fêmea.

\section{Exoplectra calcarata (Germar, 1824)}

(Figs. 33, 53)

Coccinella calcarata Germar, 1824: 610.

Exoplectra calcarata: Mulsant, 1850: 920 - 921; Crotch, 1874: 284; Korschefsky, 1932: 227; Blackwelder, 1945: 450; Gordon, 1987: 34.

Exoplectra virescens Mulsant, 1850: 920; Crotch, 1874: 284.

Fêmea. Corpo arredondado (Fig. 53), pubescência branca. Tegumento preto metálico com reflexo verde, sem máculas. Cabeça preta, peças bucais e antenas enegrecidas. Pronoto com borda látero-apical castanha, estreita. Coloração ventral e das pernas pretas, tíbias com dente lateral agudo em forma de espinho. Abdome com a base do primeiro segmento visível castanho escura, quase preta, demais segmentos avermelhados, com linha oblíqua.

Genitália. Coxitos alongados, três vezes e meia mais longos que largos. Espermateca com ramo e nódulo de comprimento subigual (Fig. 33).

Dimensões (em mm). Comprimento total: 4,83 - 5,75. Largura: $4,17-5,00$.

\section{Distribuição geográfica. Brasil (Bahia).}

Material-tipo. Dentre o material recebido do Museum für Naturkunde der Humboldt-Universitat zü Berlim, Berlim, Alemanha havia dois exemplares indicados como síntipos. O primeiro com as seguintes etiquetas: uma azul clara [Bahia. Tello], uma verde: [Hist. Coll. (Coleoptera), Nr. 4692 Exoplectra calcarata Germ., Bahia, Sellow, Zool. Mus. Berlin] e uma vermelha: [Syntypus Coccinella calcarata Germar, 1824, labeled by MNHUB 2005], este exemplar é designado aqui como lectótipo. O segundo com as seguintes etiquetas: uma azul clara, uma branca: [4692], uma verde: [Hist. Coll. (Coleoptera), Nr.

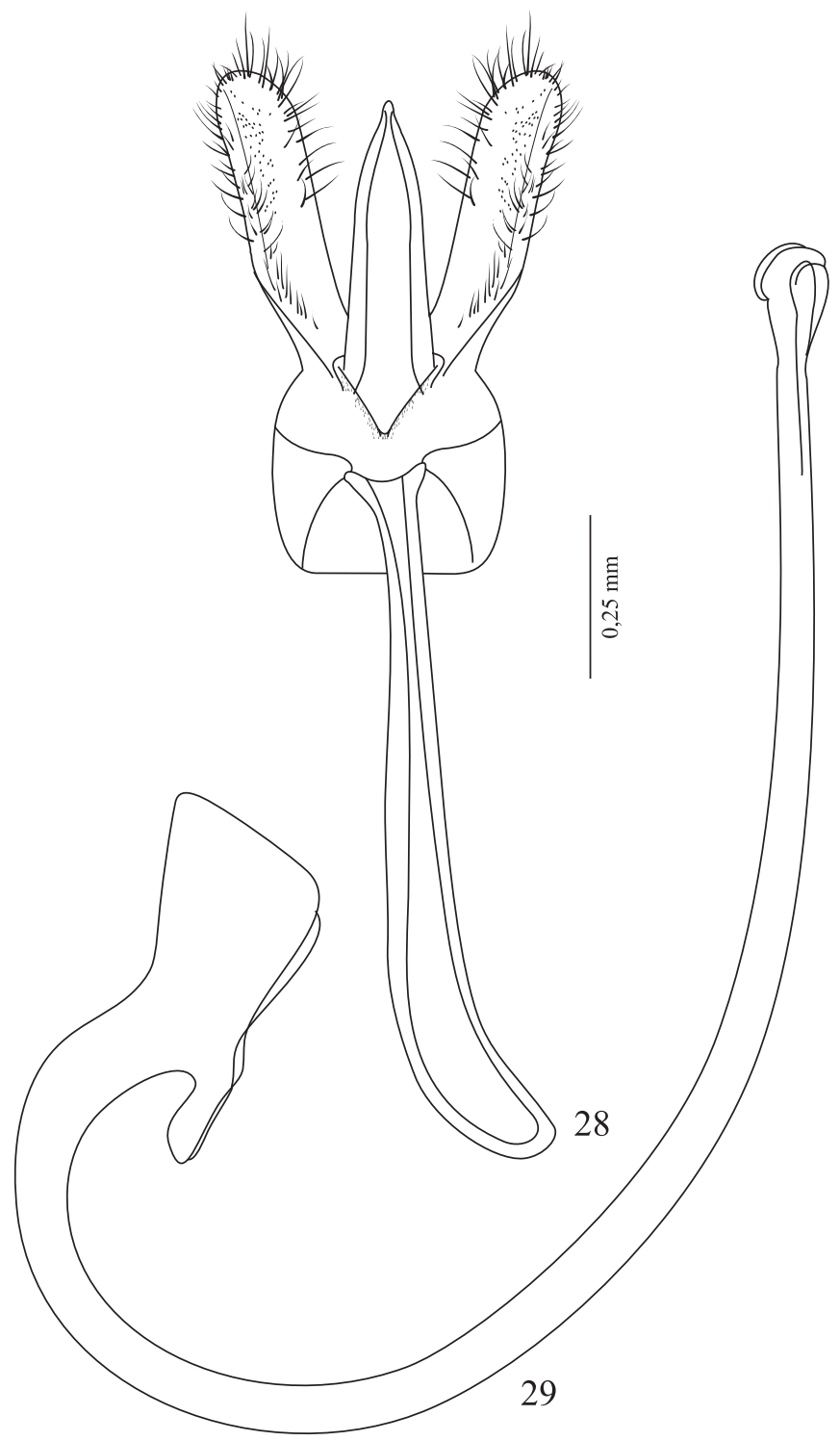

Figs. 28-29. Exoplectra batesii Crotch, 1874. Genitália do macho: 28, tégmen; 29, sifão. 


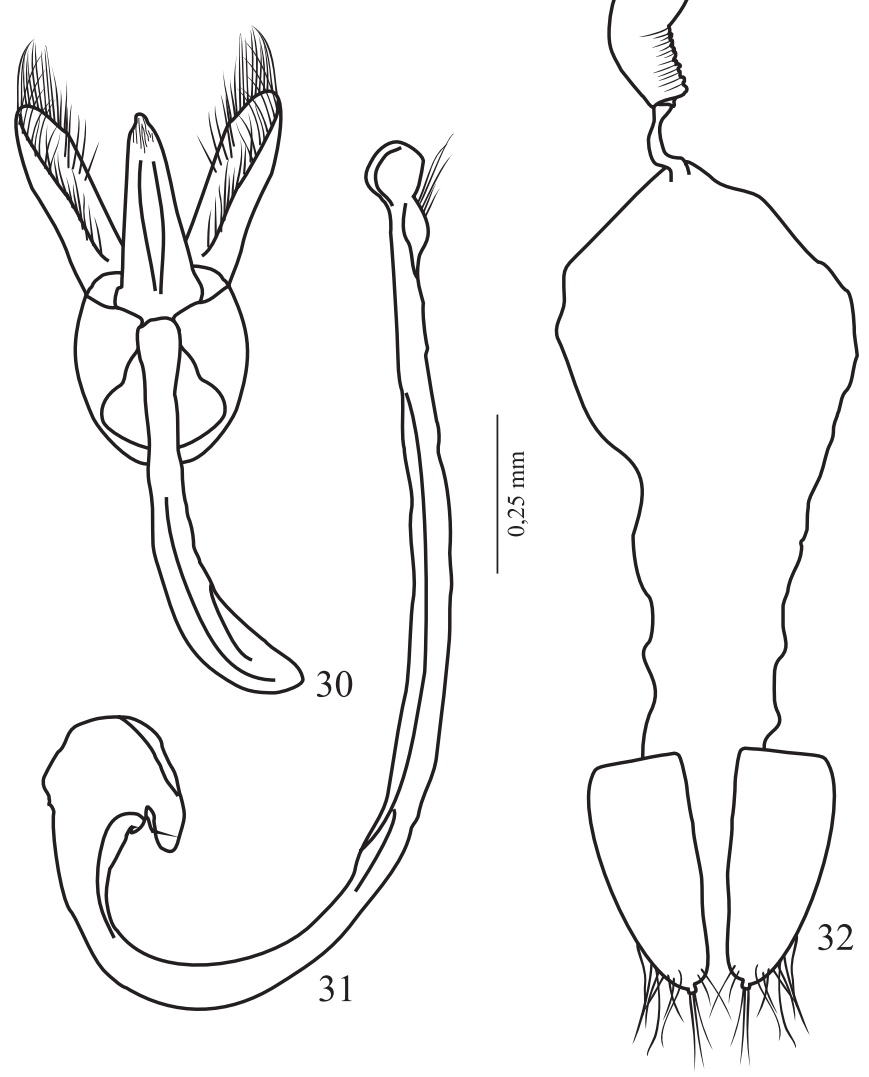

Figs. 30-32. Exoplectra brasiliensis Nunenmacher, 1912. Genitália do macho: 30, tégmen; 31, sifão; 32, genitália da fêmea.

4692, Exoplectra calcarata Germ., Brasil. V. Olfers, Zool. Mus. Berlin] e uma vermelha: [Syntypus Coccinella calcarata Germar, 1824, labeled by MNHUB 2005], designado aqui como paralectótipo.

Material examinado. BRASIL. Bahia. Sem data, sem coletor, 1 lectótipo; sem localidade, Sem data, 1 paralectótipo (MNHUB).

Discussão taxonômica. Exoplectra calcarata assemelhase a $E$. columba sp. nov. pela coloração, porém diferencia-se pela forma do corpo arredondada e tamanho maior, pubescência, dente da tíbia e padrão da genitália da fêmea.

\section{Exoplectra coccinea (Fabricius, 1801)}

(Figs. 34, 54)

Coccinella coccinea Fabricius, 1801: 35; Schonherr, 1808: 152.

Exoplectra coccinea: Chevrolat, 1844; Mulsant, 1850: 924; Linnaeus,

1758: 262; Crotch, 1874: 285; Korschefsky, 1932: 228;

Blackwelder, 1945: 450; Gordon, 1987: 34.

Exoplectra coccinea var. heydeni: Crotch, 1874:285 (error).

Exoplectra ab. armipes Chevrolat; Mulsant, 1850: 924; Korschefsky, 1932: 228.

Fêmea. Corpo arredondado (Fig. 54), pubescência branca. Tegumento alaranjado. Pronoto com borda látero-apical translúcida. Coloração ventral e das pernas alaranjada, tíbias com dente lateral obtuso. Abdome vermelho amarelado, com linha oblíqua.
Genitália. Coxitos alongados, duas vezes mais longos que largos e subtriangulares. Espermateca com ramo mais curto que o nódulo (Fig. 34).

Dimensões (em mm). Comprimento total: 3,67 - 3,75. Largura: $3,00-3,33$.

Distribuição geográfica. Guiana Francesa (Caiena); Suriname; Colombia; Brasil (Amazonas, Pará, Bahia, São Paulo).

Material-tipo. O material-tipo pertencente ao Zoological Museum, University of Copenhagen (ZMUC), Dinamarca, foi estudado e possui as seguintes etiquetas: uma vermelha [TYPE], uma branca [C: coccinea, ex. Am: Mer: Schmid], uma branca [LECTOTYPE, Coccinella coccinea Fabricius, Gordon 1986]. Como esta designação não foi publicada, designamos aqui este exemplar como lectótipo.

Dentre o material recebido do United States National Museum, Washigton D. C., Estados Unidos, havia um exemplar de Exoplectra coccinea, com as seguintes etiquetas: brancas: [4], [Republica Surinam; April, 1951], [Colector F. J. Simmonds] e [Homótipo Coccinella coccinea Fabricius; Gordon, 1986].

Material examinado. AMÉRICA MERIDIONAL(=América do Sul). Sem data, sem coletor, 1 exemplar lectótipo (ZMUC). BRASIL. Amazonas. Iguapó, sem data, J. Weise col., 1 espécime (MNHUB). SURINAME. sem localidade, IV.1951, F. J. Simmonds coll, 1 espécime †, Chpn., 1951 det; sem data, sem coletor, 1 homótipo + , Gordon 1986 det. (USNM).

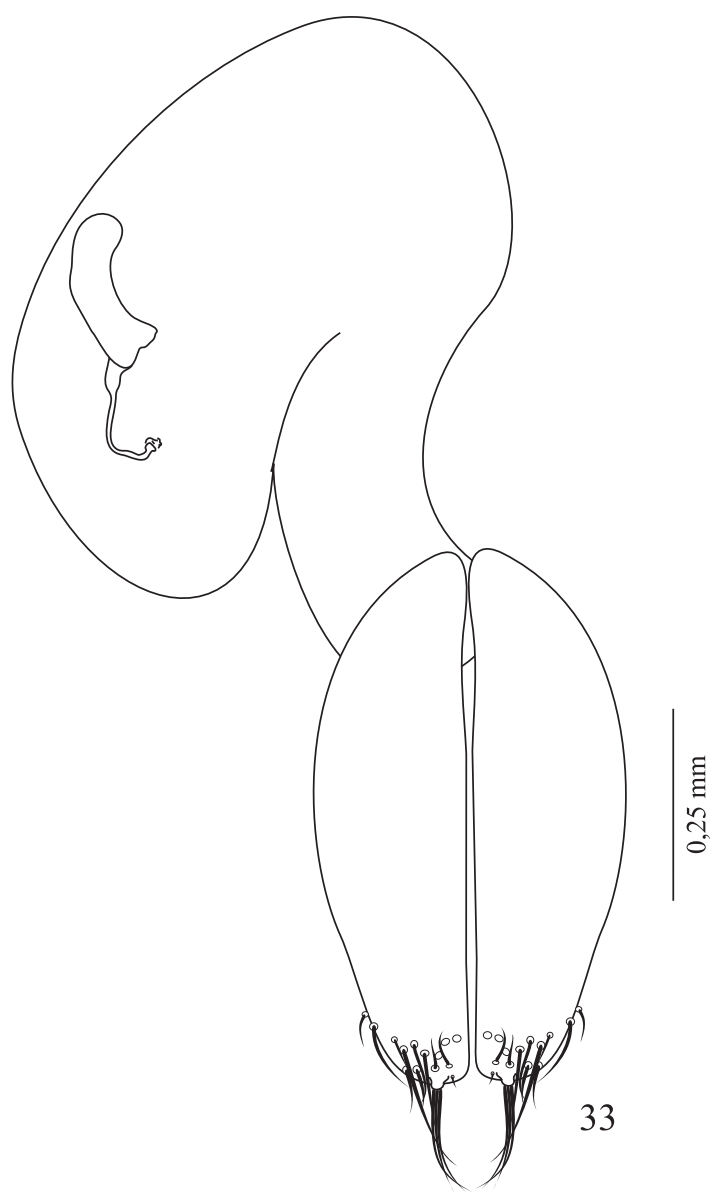

Fig. 33. Exoplectra calcarata (Germar, 1824). Genitália da fêmea. 


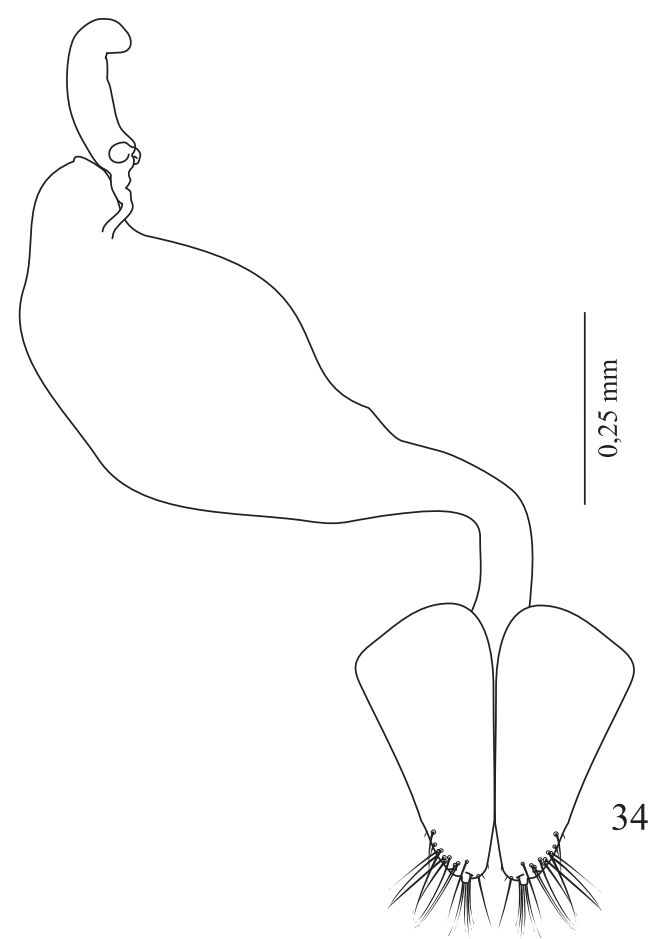

Fig. 34. Exoplectra coccinea (Fabricius, 1801). Genitália da fêmea.

Discussão taxonômica. Assemelha-se a E. heydeni pelo padrão de coloração sem máculas e pela presença de linha oblíqua, porém difere dela e das demais espécies do gênero pela coloração alaranjada e pela genitália da fêmea.

\section{Exoplectra companyoi Mulsant, 1850 sp. rev.}

(Figs. 35 - 36, 55)

Exoplectra companyoi Mulsant, 1850: 919, 920.

Exoplectra luteicornis: Crotch, 1874: 284.

Macho. Corpo arredondado (Fig. 55), pubescência amarelada. Tegumento preto metálico, com reflexo verde. Cabeça preta, peças bucais e antenas enegrecidas com as extremidades avermelhadas. Pronoto com borda látero-apical castanha. Coloração ventral e das pernas pretas. Tíbias com dente lateral agudo em forma de espinho. Abdome com o primeiro segmento visível, preto, demais avermelhado, sem linha oblíqua.

Genitália. Parâmeros com cerdas longas, distribuídas predominantemente na face interna, cerca de duas vezes mais longos que lobo médio, este mamiliforme no ápice (Fig. 35). Sifão longo com ápice arredondado (Fig. 36).

Dimensões (em mm). Comprimento total: 5,42 - 5,83; Largura: 4,92-542.

\section{Distribuição geográfica. Brasil (Chapada).}

Material-tipo. Dentre o material recebido do United States National Museum, Washigton D. C., Estados Unidos, havia um exemplar de Exoplectra companyoi, com as seguintes etiquetas brancas: [Oct],
[Chapada Brasil Acc n. 2966], [Exoplectra companyoi Muls, det Dieke, 1954], [G. H. Dieke; Coll'n. 1965] e [Homotype Exoplectra companyoi Muls; Gordon, 1970].

Material examinado. BRASIL. Chapada, Sem data, sem coletor, Nr. 2966, 2 espécimes (1 $\sigma^{\pi}$ homótipo) (USNM).

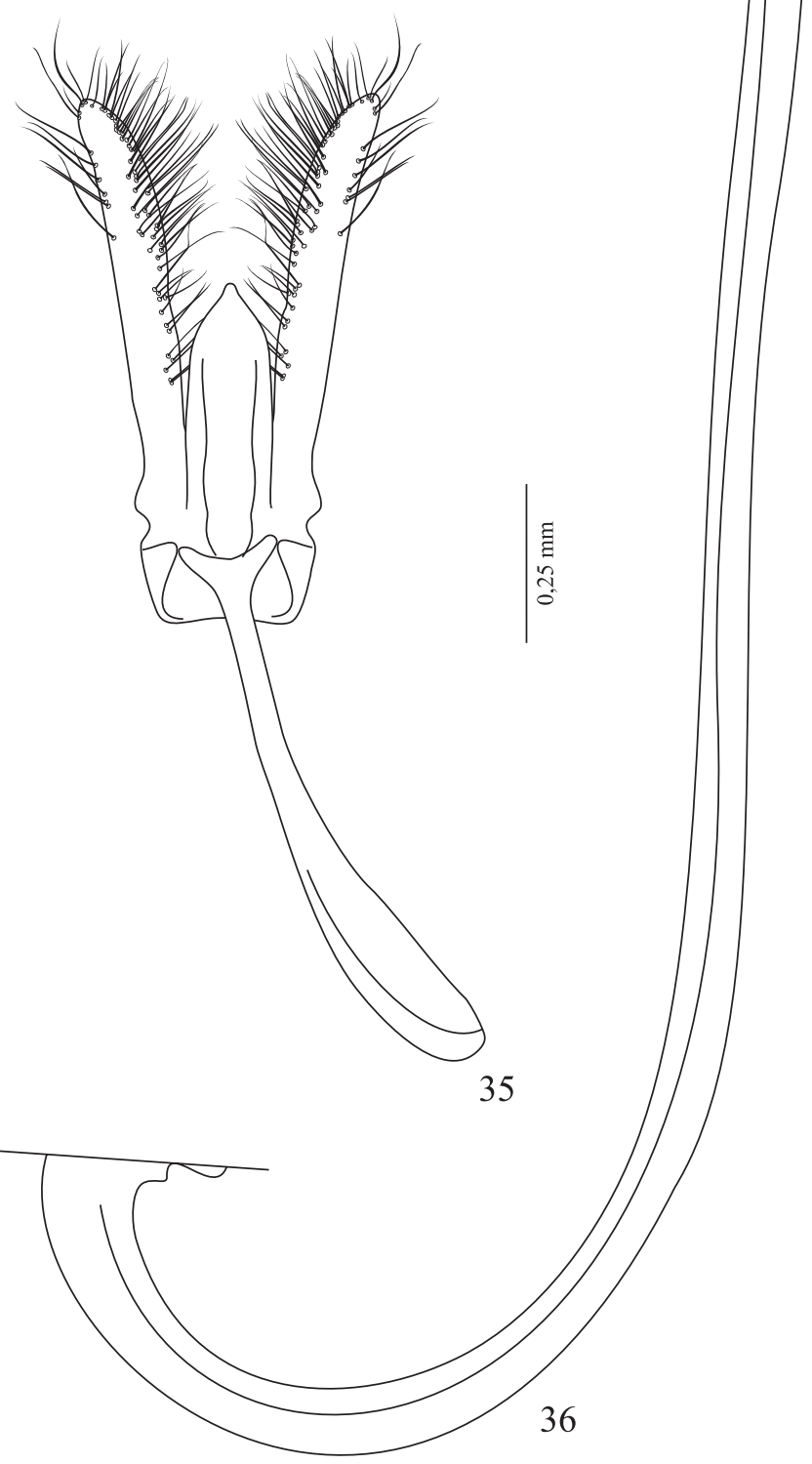

Figs. 35-36. Exoplectra companyoi Mulsant, 1850. Genitália do macho: 35 , tégmen; 36 , sifão. 


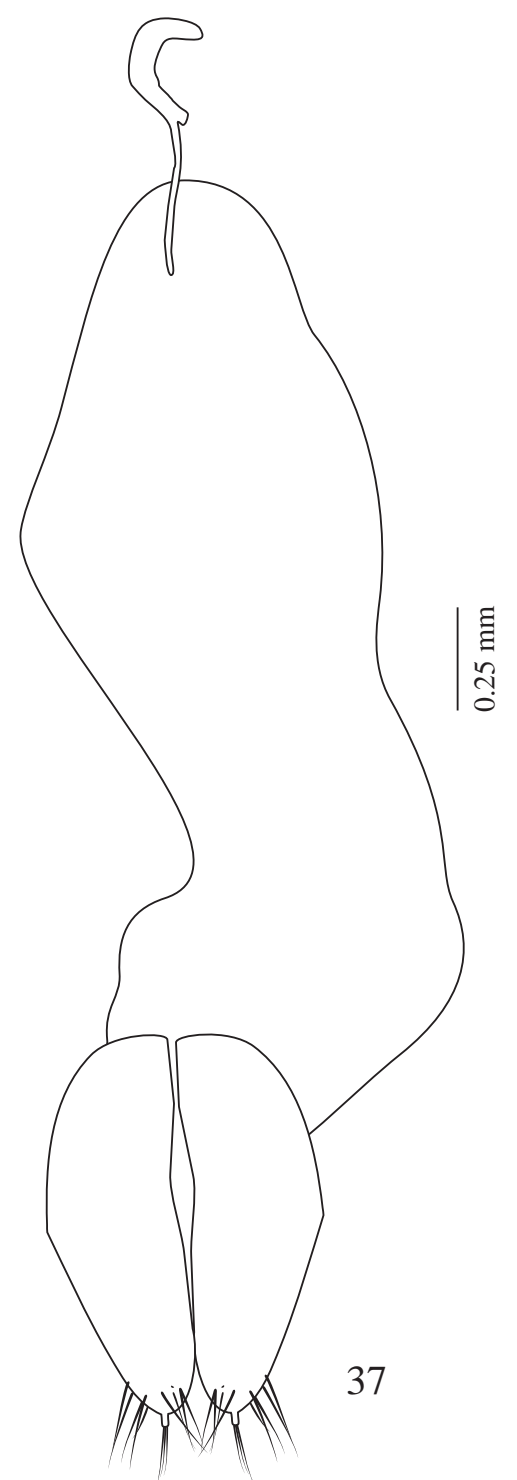

Fig. 37. Exoplectra dubia Crotch, 1874. Genitália da fêmea.

Comentários. Exoplectra companyoi foi descrita por Mulsant em 1850 que na mesma página descreveu $E$. luteicornis. O primeiro revisor do gênero, Crotch (1874) considerou E. companyoi como espécie válida e E. luteicornis como sinônimo júnior. Tanto Korchefsky (1932) como Blackwelder (1945) listaram erroneamente E. luteicornis como espécie válida, contrariando o primeiro revisor (Crotch 1874) e colocando E. companyoi como sinônimo. Neste trabalho ambas as espécies foram estudadas e diferem entre si. $E$. companyoi é revalidada e E. luteicornis retirada provisoriamente do gênero.

Quando comparada com E. metallescens assemelha-se pela forma e coloração do corpo e difere da mesma pelo tamanho menor e genitália do macho que não apresenta no ápice do sifão bolsa prepucial e ampola desenvolvida como observado em E. metallescens.
Exoplectra dubia Crotch, 1874

(Figs. 37, 56)

Exoplectra dubia Crotch, 1874: 284; Korschefsky, 1932: 228; Blackwelder, 1945: 450; Gordon, 1987: 34.

Fêmea. Corpo oval (Fig. 56), pubescência branca. Tegumento preto metálico com reflexo bronze. Pronoto com borda látero-apical avermelhada e translúcida, estreita. Cabeça, peças bucais e antenas pretas. Meso e metanoto enegrecidos. Tíbias com dente lateral agudo em forma de espinho. Abdome avermelhado, com linha oblíqua.

Genitália. Coxitos alongados, três vezes mais longos que largos. Espermateca com ramo e nódulo subiguais (Fig. 37).

Dimensões (em mm). Comprimento total: 5,80. Largura: 5,00.

Distribuição geográfica. Brasil (Paraná).

Material-tipo. Gordon (1985) indica em seu catálogo que não há exemplares na coleção de Crotch.

Material examinado. BRASIL. Paraná. Ponta Grossa, X.1942, 1 espécime, J. Guerin coll, J. Guerin, 1943 det. (IBSP).

Discussão taxonômica. Exoplectra dubia assemelha-se a Exoplectra batesii pela forma do corpo, coloração e pubescência branca, porém difere por possuir reflexo bronze, presença de linha oblíqua.

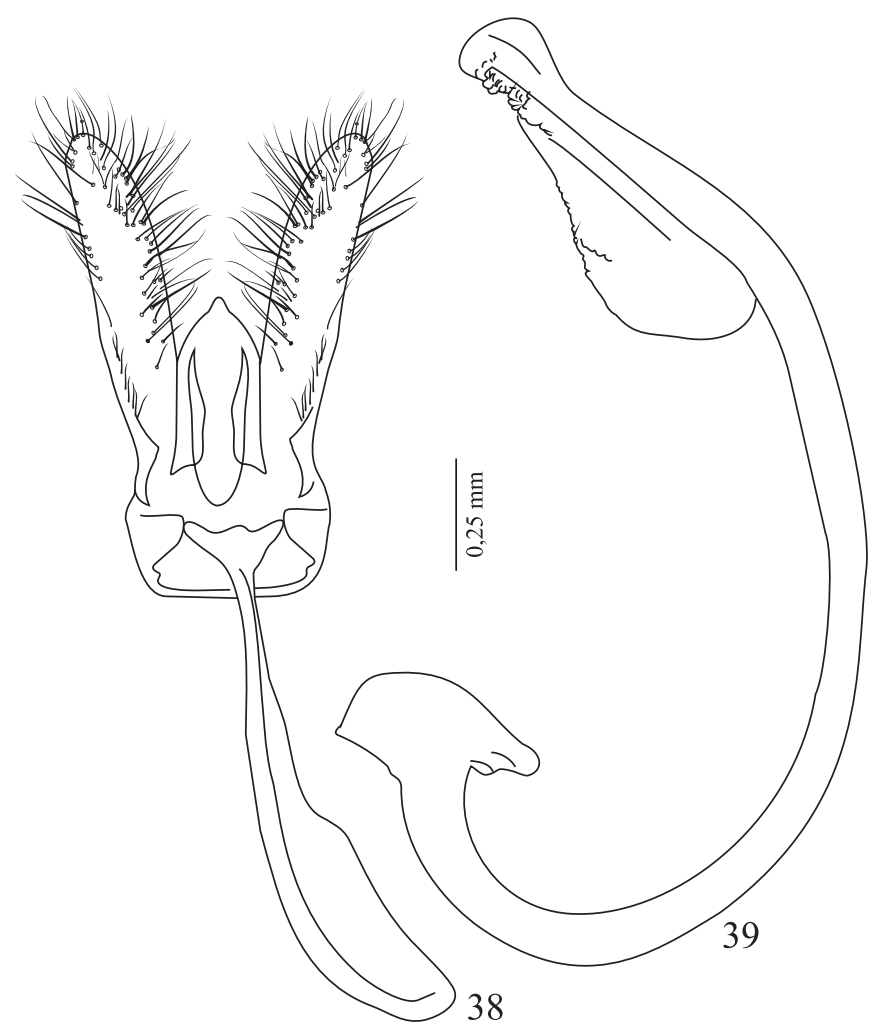

Figs. 38-39. Exoplectra metallescens Mulsant, 1850. Genitália do macho: 38 , tégmen; 39 , sifão. 


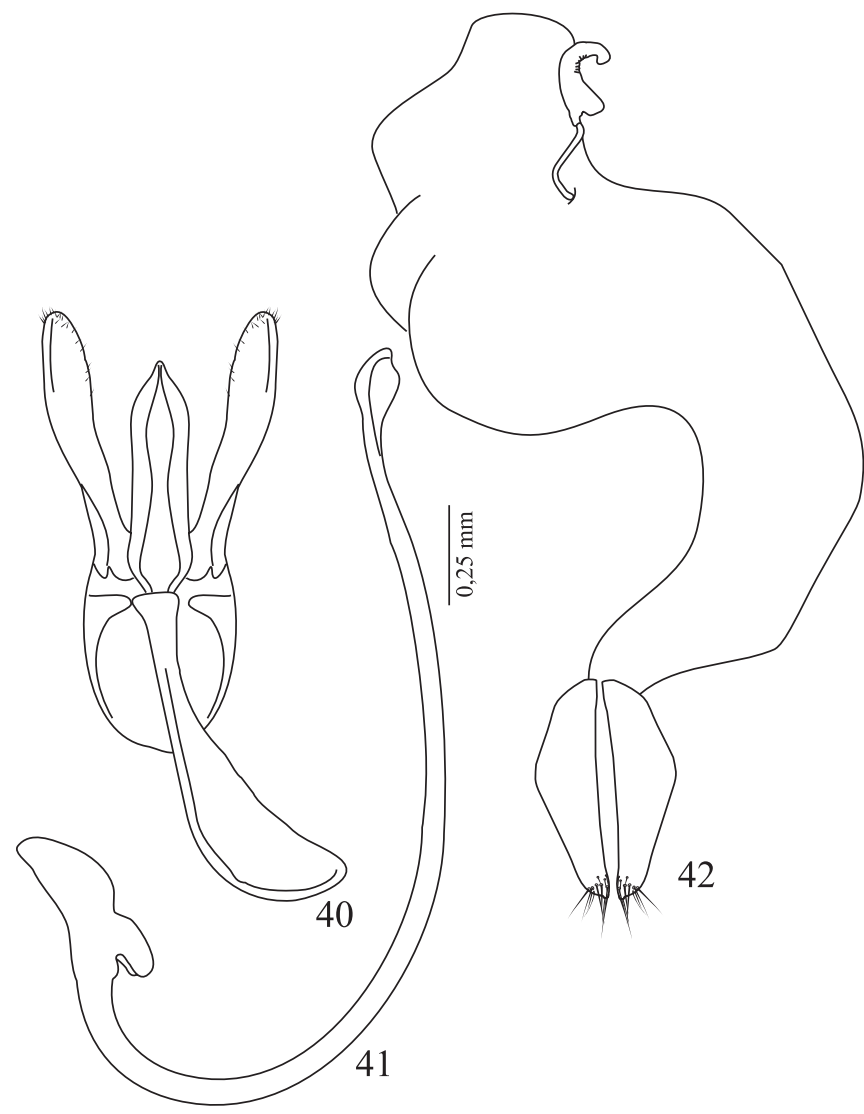

Figs. 40-42. Exoplectra heydeni Mulsant, 1850. Genitália do macho: 40, tégmen; 41, sifão; 42, genitália da fêmea.

\section{Exoplectra metallescens Mulsant, 1850}

(Figs. 38-39, 57)

Exoplectra metallescens Mulsant, 1850: 918; Crotch, 1874: 284. Exoplectra fucosa: Crotch, 1874: 284; Korschefsky, 1932: 228 (error); Blackwelder, 1945: 450 (error); Gordon, 1987: 34.

Exoplectra metallica Dejean, 1837:461; Mulsant, 1850: 918.

Macho. Corpo arredondado (Fig. 57), pubescência amarelada. Tegumento preto metálico, com reflexo verde. Cabeça preta, peças bucais e antenas enegrecidas. Pronoto com borda látero-apical avermelhada. Coloração ventral e das pernas pretas. Tíbias com dente lateral agudo em forma de espinho. Abdome com o primeiro segmento preto, demais avermelhados, sem linha oblíqua.

Genitália. Parâmeros muito mais longos que lobo médio, este mamiliforme no ápice (Fig. 38). Sifão longo com ápice arredondado, com bolsa prepucial e ampola desenvolvida (Fig. 39).

Dimensões (em mm). Comprimento total: 6,58 - 7,33. Largura: $5,78-6,67$.

Distribuição geográfica. Brasil.

Material-tipo. O lectótipo ơ de Exoplectra metallescens foi emprestado do Departament of Zoology, University of Cambridge,
Cambridge, Inglaterra e possui os seguintes dados: três etiquetas brancas: [TYPE, metallescens Chev], [LECTOTYPE, Exoplectra metallescens Muls, 1850, Gordon 1987] e [University Museum of Zoology, CAMBRIDGE].

Material examinado. BRASIL. Sem localidade, Sem data, 1 espécime or lectótipo; 2 espécimes 우 (DZUC).

Comentários. Exoplectra metallescens foi descrita por Mulsant em 1850, que logo após a diagnose colocou como sinônimos E. metallica e E. angulipes: "E. metallica (en partie) Dej. Catal. P.461 (T)." e "E. angulipes, Chevrolat, Dej. 1.c.". Acima da descrição de E. metallescens, na mesma página descreveu E. fucosa. O primeiro revisor do gênero, Crotch (1874) considerou E. metallescens como espécie, sinonimizando a ela, E. fucosa. Os catálogos de Korchefsky (1932) e Blackwelder (1945) listaram erroneamente E. fucosa como espécie válida, colocando E. metallescens e E. metallica como sinônimos. Gordon (1987) em seu catálogo reconhece $E$. metallescens como válida.

Discussão taxonômica. Exoplectra metallescens assemelha-se a $E$. companyoi pela coloração preta com reflexo verde, pubescência amarelada e forma do corpo, diferindo pelo seu tamanho maior e pela genitália do macho, que apresenta o ápice do sifão projetado e com bolsa prepucial desenvolvida. Este carater também a diferencia das demais espécies do gênero.

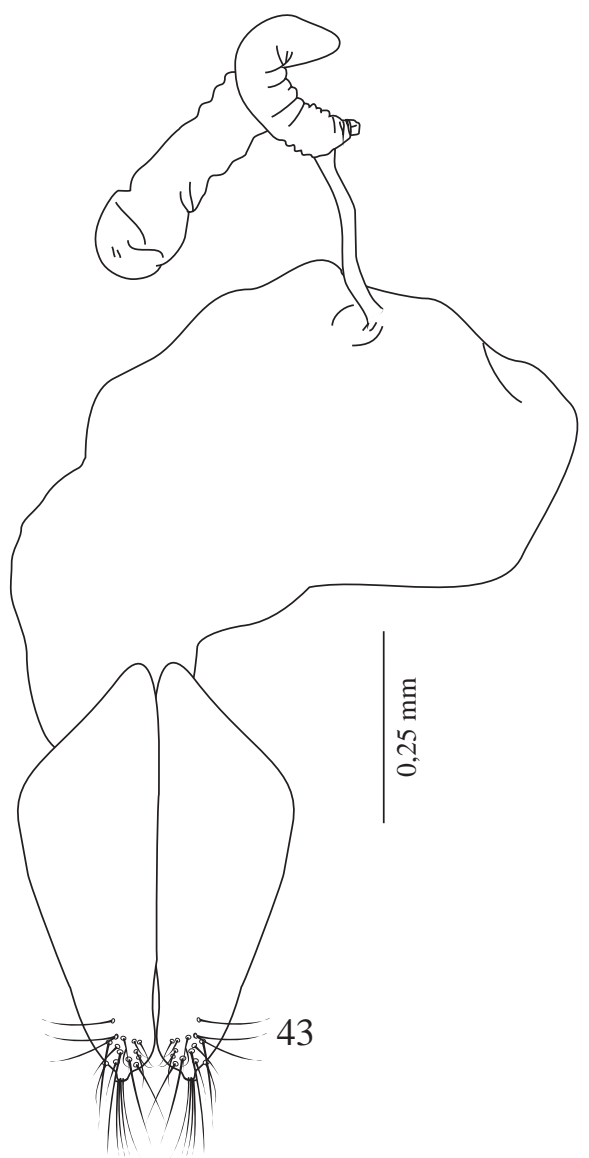

Fig. 43. Exoplectra santaremae Crotch, 1874. Genitália da fêmea. 

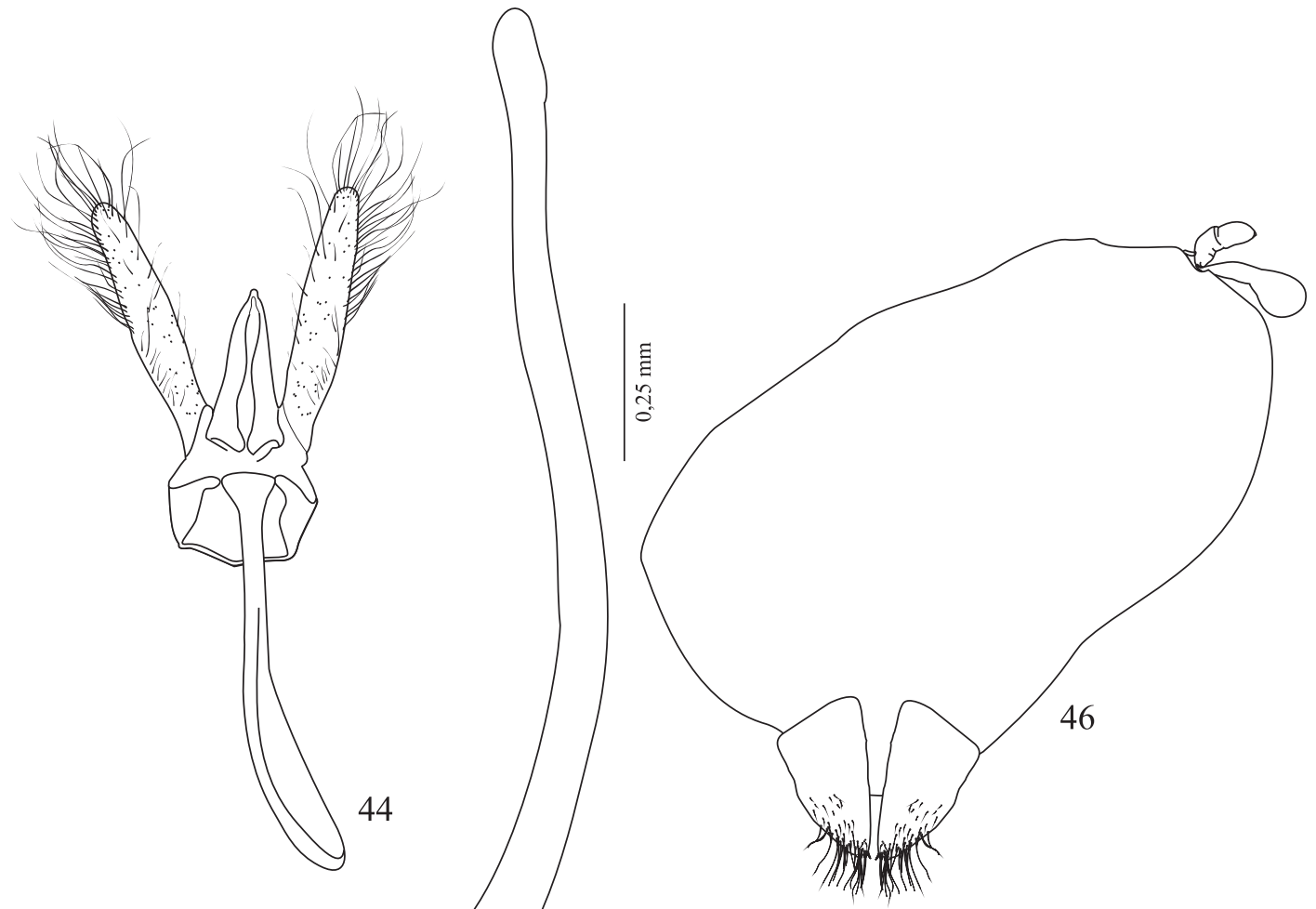

Figs. 44-46. E. columba sp. nov. Genitália do macho: 44, tégmen; 45, sifão; 46, genitália da fêmea.

Exoplectra heydeni Mulsant, 1850

(Figs. 40 - 42, 58)

Exoplectra heydeni Mulsant, 1850: 924; Korschefsky, 1932: 228; Blackwelder, 1945: 450.

Macho. Corpo arredondado (Fig. 58), pubescência branca. Tegumento avermelhado. Escutelo preto ou vermelho. Pronoto de mesma coloração. Coloração ventral avermelhada . Femur preto, tíbias com dente lateral agudo em forma de espinho. Abdome com linha oblíqua.

Genitália. Parâmeros com poucas cerdas curtas, pouco maiores que o lobo médio, este mamiliforme (Fig. 40). Sifão com cápsula alongada e com ápice arredondado (Fig. 41).

Fêmea. Semelhante ao macho.

Genitália: Coxitos alongados, três vezes mais longos que largos. Espermateca com ramo duas vezes mais longo que o nódulo (Fig.42).

Dimensões (em mm). Comprimento total: 4,50 - 5,67. Largura: $3,92-4,83$. Santo)
Material-tipo. Não foi possível o exame do material-tipo que, segundo Horn \& Kahle (1935-37) encontra-se no Institut Sant Marie, Chamond (Loire), França.

Material examinado. BRASIL. Sem localidade, sem data, Coleção J. Weise, 1 espécime, (USNM); sem localidade, sem data, Ex. coleção J. Weise, 1 espécime (MNHUB). Minas Gerais. Vitória, VIII.1937, sem coletor, 2 espécimes; IX. 1937, sem coletor, Coleção J. P. F., 2 espécimes (IBSP). Espírito Santo. sem localidade, sem data, sem coletor, Ex. coleção J. Weise, 8 espécimes; Pto. Cachoeira, 28.II.1998, 2 espécimes (MNHUB).

Discussão taxonômica. E. heydeni havia sido considerada erroneamente como variedade de E. coccinea por Crotch (1874), porém difere dela por apresentar tegumento vermelho, superfície ventral e pernas pretas, além de apresentar coxitos muito alongados e afilados. Assemelha-se a E. miniata pela forma do corpo e pubescência branca, presença de linha oblíqua e pelo padrão da genitália do macho, parâmeros com cerdas curtas e pouco maiores que o lobo médio, este mamiliforme. Diferencia-se pela ausência de máculas, dente da tíbia agudo e pela genitália da fêmea que apresenta ramo alongado, maior que o nódulo, enquanto que em E. miniata, o ramo e nódulo são curtos. 


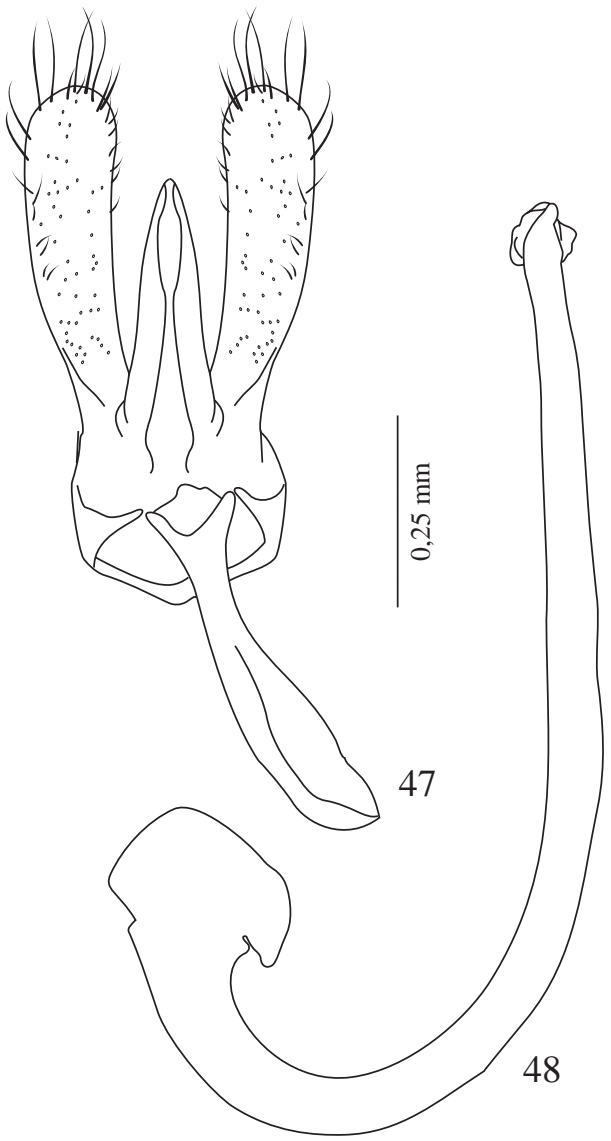

Figs. 47-48. E. bimaculata sp. nov. Genitália do macho: 47, tégmen; 48, sifão.

\section{Exoplectra miniata (Germar, 1824)}

(Figs. 1-21, 59, 63-78)

Coccinella miniata Germar 1824: 616.

Exoplectra miniata: Chevrolat, 1844: 545 (comb. nov.); Mulsant, 1850: 926; Crotch, 1874: 285; Chapuis, 1876: 242; Korschefsky, 1932: 228; Blackwelder, 1945: 451; Gordon, 1987: 34.

Macho. Corpo arredondado (Fig. 59), pubescência branca. Tegumento avermelhado. Cabeça, peças bucais e antenas avermelhadas. Pronoto avermelhado com duas máculas pretas circulares na base. Escutelo preto. Cada élitro com cinco máculas pretas circulares: a primeira sobre o calo umeral; a segunda no disco central, próxima à sutura; a terceira no terço apical, próxima à sutura; a quarta látero-apical, próxima a margem externa e a quinta no ápice, junto à sutura. Coloração ventral avermelhada, fêmures pretos. Tíbias avermelhadas, com dente obtuso. Abdome vermelho, com linha oblíqua.

Genitália. Parâmeros com cerdas curtas, pouco maiores que o lobo médio, este mamiliforme (Fig. 19). Sifão com cápsula alongada e com ápice arredondado (Fig. 20).

Fêmea. Semelhante ao macho.

Genitália. Coxitos alongados, pouco mais que três vezes mais longos que largos. Espermateca com ramo alongado e nódulo curto (Fig. 21).
Dimensões (em mm). Comprimento total: 3,75 - 5,58. Largura: $3,25-4,83$.

Distribuição geográfica. Brasil (Minas Gerais, Distrito Federal, Espírito Santo, Rio de Janeiro, São Paulo e Paraná).

Material-tipo. Dentre os quatro exemplares recebidos do Museum für Naturkunde der Humboldt-Universitat zü Berlim, Berlim, Alemanha, como síntipos, designamos aqui o lectótipo com as seguintes etiquetas: branca [4664], verde [Hist. Coll. (Coleoptera), Nr. 4664, Exoplectra miniata Germ., Brasil, V. Olfers + Sellow, Zool. Mus. Berlin], vermelha [Syntypus, Coccinella miniata Germar, 1824, labelled by MNHUB 2005], branca [miniata Germ. Braz.] (Fig. 130); e os três outros exemplares citados no material examinado, como paralectótipos.

Material examinado. Sem localidade, sem data e sem coletor, Coll. L. W. Schaufuß, 2 espécimes; sem data e sem coletor, 1 espécime; sem data, Drake, J. Weise coll., 2 espécimes (MNHUB); IV.1985, P. Sandig leg., 1 espécime (USNM). BRASIL. Sem data, Germar, 4 espécimes; sem data, sem coletor, Mus. Westerm. 2 espécimes; sem data, Dal Borgo, 2 espécimes (ZMUC); sem data, sem coletor, 4 espécimes (MNHUB); Sem data, E. M. Melo, Coleção Campos Seabra, 1 espécime (MNRJ); Sem data, sem coletor, 1 espécime; VIII. 1901, C. Bruch, Coll. J. Weise, 2 espécimes (MNHUB). Minas Gerais. Belo Horizonte, sem data, 1 n. 351, Oscar Monte leg., 5 espécimes (IBSP); sem data, Oscar Monte leg., 255/ FCC-222, 1 espécime (DZUP); III.1961, H. Espinola col., 1 exemplar (MNRJ). Conceição da Aparecida, Fazenda São José, II.1960, J. C. M. Carvalho leg., 1 espécime (MNRJ). Juiz de Fora, 27.VII.1940, 1 espécime; V.1943, Araújo leg., 3 espécimes (IBSP); 5.III.1957, Aristoteles da Silva leg., Coleção Campos Seabra, 1 espécime (MNRJ); 17.XI.1974, G. S. Andrade leg., 3 espécimes (FZRS). Ijaci, 25.IX.2000, L. V. C. Santa-Cecilia, 1 espécime (DZUP). Lagoa S. (=Lagoa Santa), sem data, Rhdt., 20 espécimes (ZMUC); Lambary, II.1924, 15454, J. Guerin leg. 1 espécime (IBSP); Manhuassu, 15.XII.1936, sem coletor, 3 espécimes (MNRJ). Mar de Espanha, 2728.II.1962, sem coletor, J. Bechyné leg., Convênio DZSP-Goeldi, 3 espécimes (MZSP). Monte Alegre, Fazenda Santa Maria, alt. 1.100 mts., 24-30.XI.1942, F. Lane leg., 2 espécimes (MZSP). Santa Bárbara, Serra do Caraça, 23-25.XI.1960, Araújo e Martins leg., 1 espécime; Engenho, 800 m., XI. 1961, 3 espécimes; 1800 m., XI.1961, Kloss, Lenko, Martins \& Silva leg., 5 espécimes (MZSP). Santa Rita Caldas, XII.1953, Pe. Pereira leg., 3 espécimes (MZSP). Viçosa, sem data, Oscar Monte leg., n.438, 1 espécime (IBSP). Brasilia. Distrito Federal, sem data, Dr. Will, 1 espécime (MNHUB). Espírito Santo. Sem localidade, sem data, sem coletor, Coleção J. Weise, 1 espécime (MNHUB). Santa Teresa, 29.I.1964, 71 espécimes; 5.II.1964, 2 espécimes; 12.X.1964, 4 espécimes; 4. X. 1964, 1 espécime, C. Elias leg. (DZUP); 26.X.1964, 6 espécimes; XI.1964, 2 espécimes; 03.XII.1964, 2 espécimes; 6.XI.1966, 3 espécimes; 28.XI.1966, 1 espécime, C. T.\& C.Elias leg.; 20.XII.1966, Elias Tadeu, 1 espécime; 01-03.XI.1968, 1 espécime, C. \& C. T. Elias. S. J. Petrópolis, 12.II.1964, C. Elias leg., 1 espécime (DZUP). Rio de Janeiro. Angra dos Reis, IV. 1940, L. Travassos leg., Dieke 1954 det.. 1 espécime (DZUP). Jussara, IX.1934, D. Mendes, 1 espécime (MNRJ); IX.1935, 8075, D. Mendes, 2 espécimes (DZUP). Mendes, sem data, sem coletor, 2 espécimes (MNRJ); I.1943, sem coletor, 4 espécimes (MNCI); Rio de Janeiro, Serra dos Órgãos, XI.1940, sem coletor, 1 espécime (MNRJ); B. do Pirahy, sem data, sem coletor, 1 espécime; B. do Mato, sem data, M. Rosa, 1 espécime; S. Bento, 20.X.1956, Caco leg., 1 espécime; Corcovado, X.1957, sem coletor, 1 espécime; XII.1958, Alvarenga \& Seabra, 1 espécime; X.1959, 1 espécime; Guanabara (atual Rio de Janeiro), X.1963, 1 espécime, M. Alvarenga Coll. (USNM); Estrada das Paineiras, 22.X.1960, A. Pirachi col., 1 espécime; XII.1961, 1 espécime, Alvarenga e Seabra leg.; X.1966, Alvarenga \& Seabra, 1 espécime + ; XI.1966, 1 espécime; VIII.1967, 1 espécime; X.1967, Alvarenga \& Seabra, Coleção M. Alvarenga, 1 espécime; 06.X.1967, Moure \& Seabra, 1 espécime; XI.1967, Alvarenga \& Seabra, 1 espécime; IX.1970, Alvarenga \& Seabra, Coleção M. Alvarenga, 1 espécime (DZUP); 

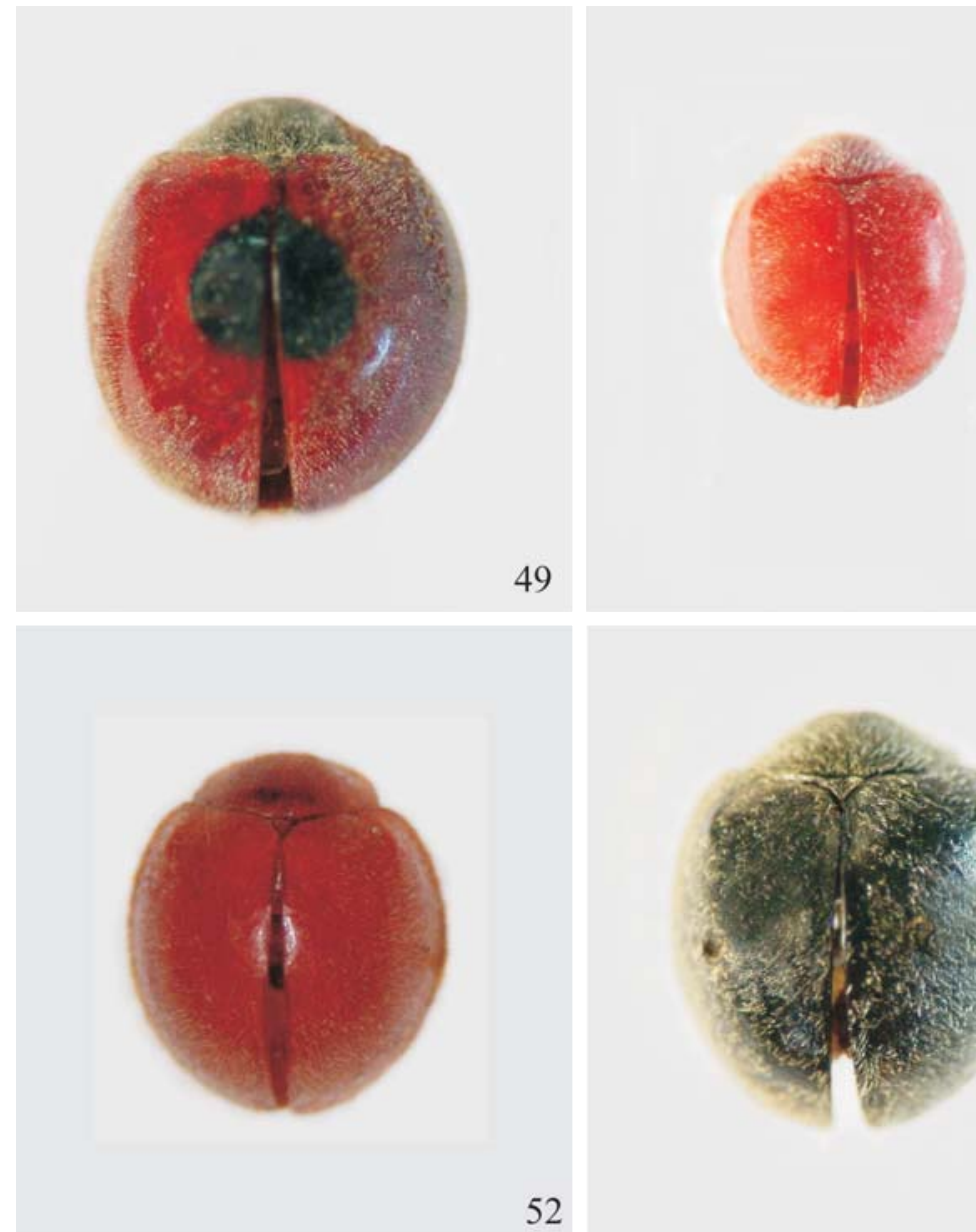

50

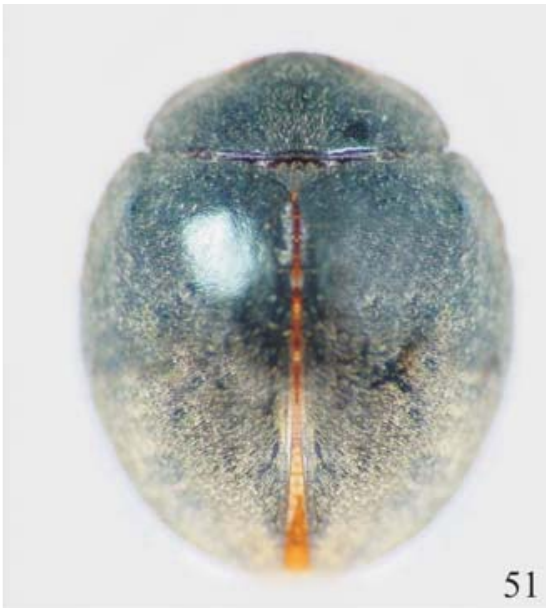

52
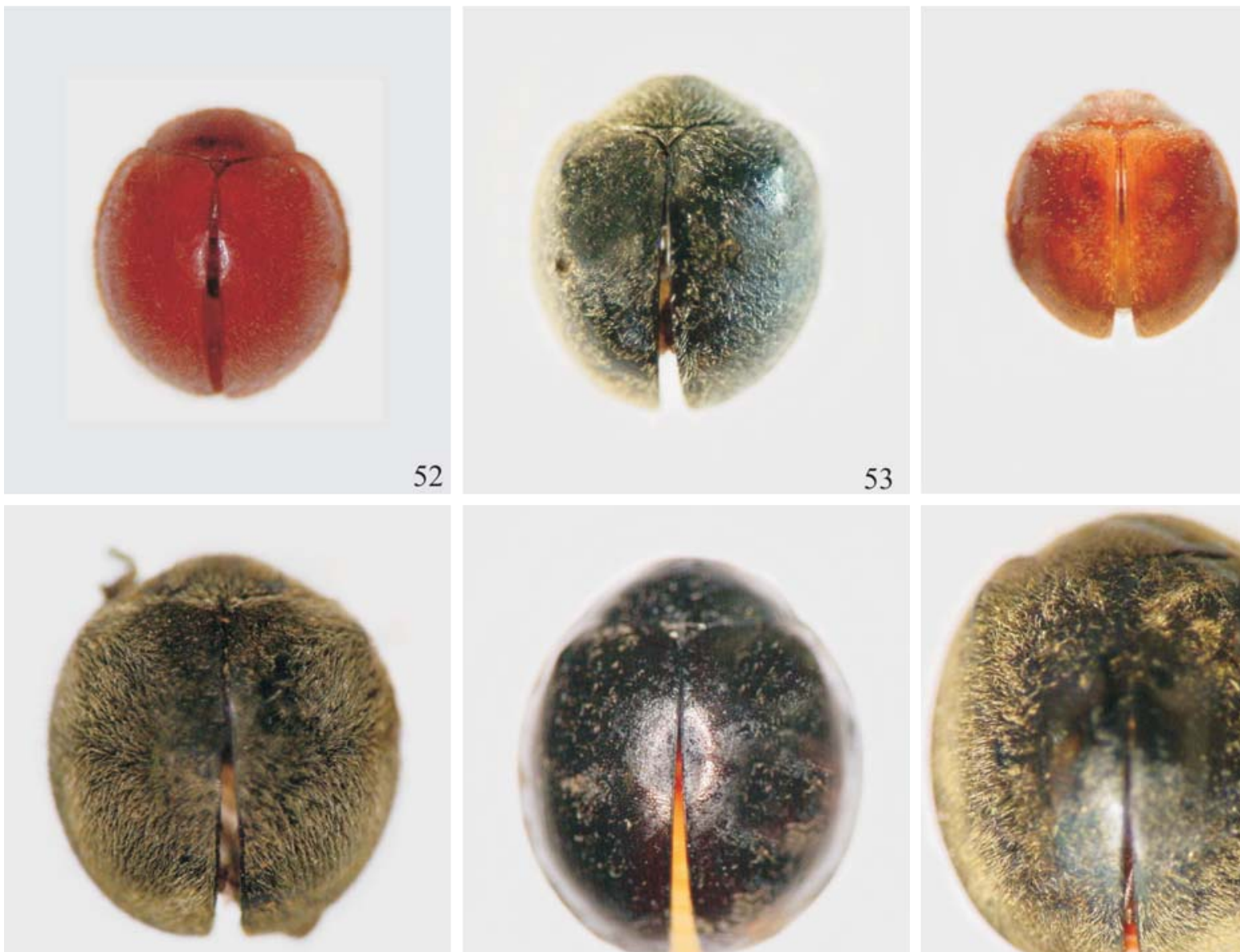

55
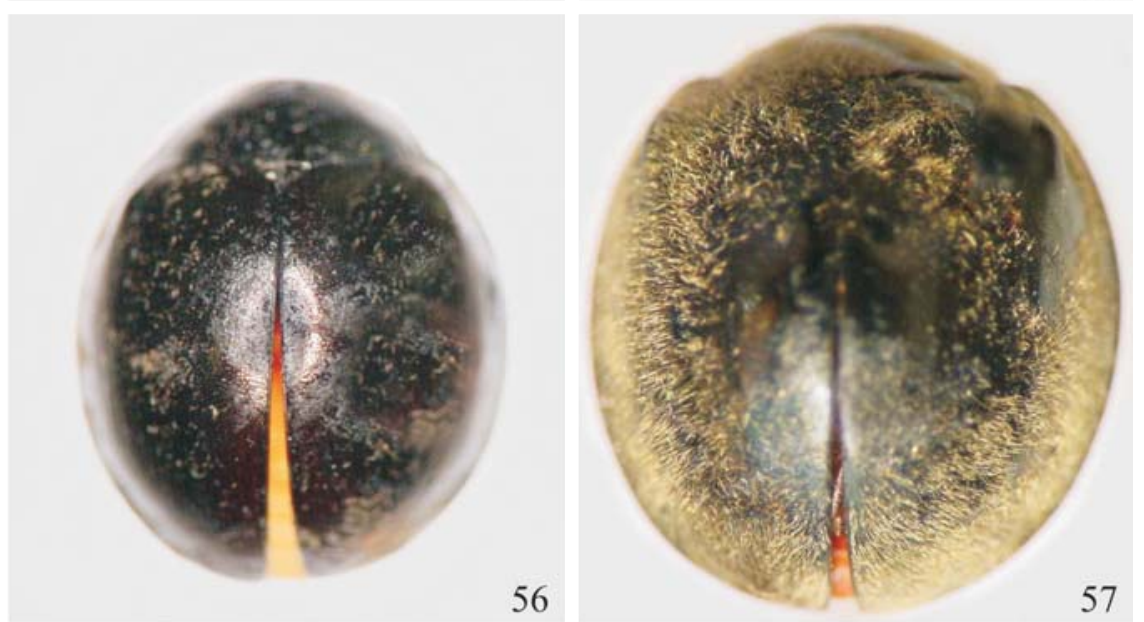

Figs. 49-57. 49, Exoplectra amazonica Crotch, 1874; 50, Exoplectra angustifrons Weise, 1895; 51, Exoplectra batesii Crotch, 1874; 52, Exoplectra brasiliensis Nunenmacher, 1912; 53, Exoplectra calcarata Germar, 1824; 54, Exoplectra coccinea (Fabricius, 1801); 55, Exoplectra companyoi Mulsant, 1850; 56, Exoplectra dubia Crotch, 1874; 57. Exoplectra metallescens Mulsant, 1850.

26.IX.1972, C. A . Campos Seabra, 1 espécime (MNRJ); V. 1975, M. A Monné, 1 espécime; 17.X.1975, 2 espécimes; 27.X. 1975, 3 espécimes; 15.X.1976, M. A. Monné e C. A. Campos Seabra, 3 espécimes; 13.IX.1975, M. A . Monné, 1 espécime (MNRJ); Represa Rio Grande, XII.1960, Werner e Alvarenga, 1 espécime; I.1961, 1 espécime; 25.III.1961, 3 espécimes; III.1961, F.M.Oliveira,1 espécime; IV.1961, F. M. Oliveira, Coleção M. Alvarenga, 1 espécime; IX. 1961, F. M.
Oliveira, 1 espécime; XII.1961, Seabra \& Alvarenga, 1 espécime; V.1962, M. Alvarenga col., Ex. coleção M. Alvarenga, 1 espécime; XI.1966, Alvarenga \& Seabra, Col. Alvarenga, 1 espécime; 10.XI.1966, F. M. Oliveira leg., 3 espécimes; 09.I.1967, 1 espécime + ; 03.II.1967, 1 espécime; 20.V. 1967, 3 espécimes; 20.X.1967, 1 espécime; 15.II.1967, F. M. Oliveira, 3 espécimes; V.1968, F. M. Oliveira, Coleção M. Alvarenga, 1 espécime (MZSP); 20.IX.1960, 1 espécime; XII.1960, 


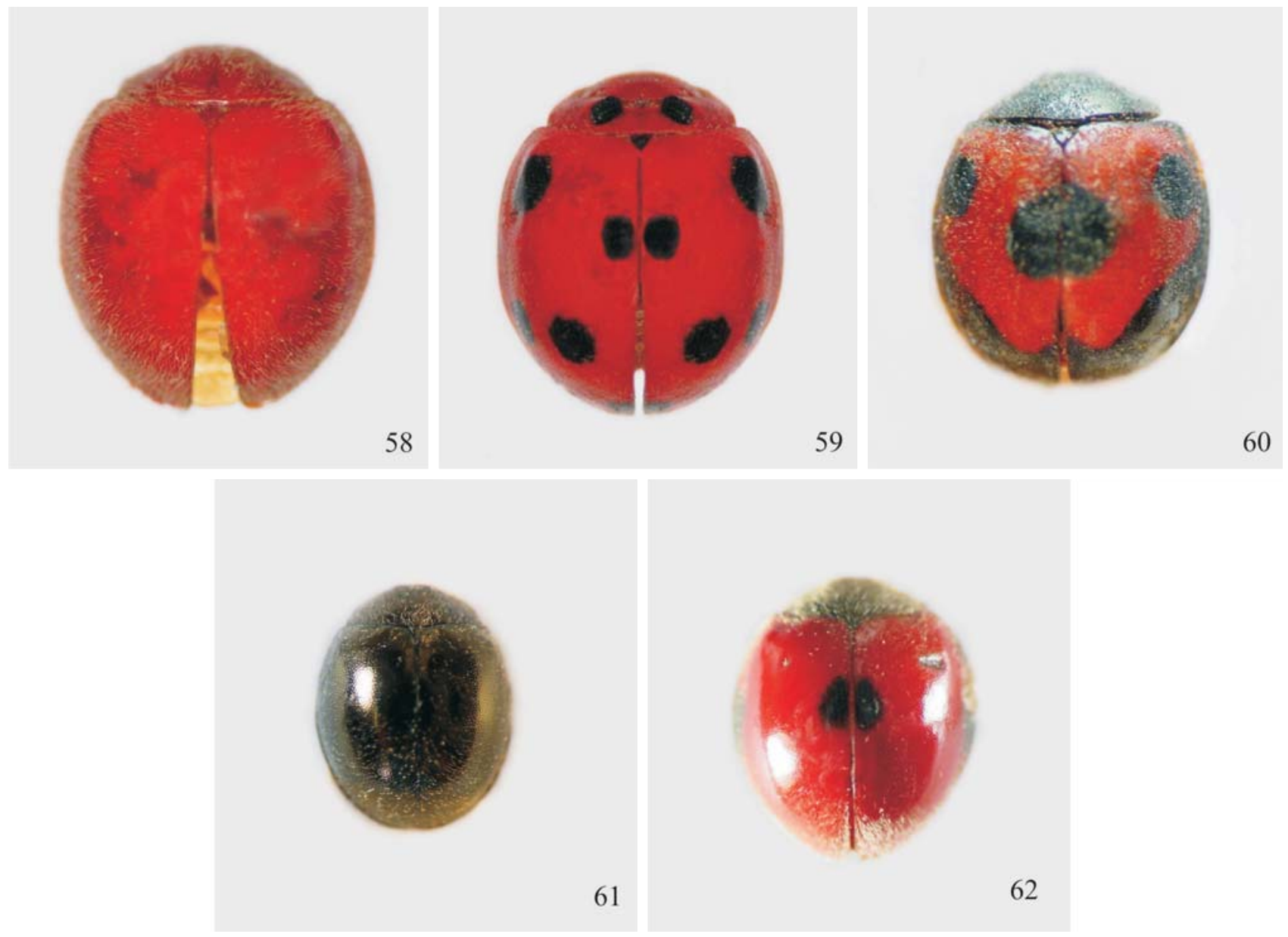

Figs. 58-62. 58, Exoplectra heydeni Mulsant, 1850; 59, Exoplectra miniata (Germar, 1824); 60, Exoplectra santaremae Crotch, 1874; 61, E. columba sp. nov.; 62, E. bimaculata $\mathbf{s p . ~ n o v . ~}$

1 espécime; I.1961, 1 espécime; X.1961, 1 espécime; II.1961, 3 espécimes; III. 1961, 1 espécime; XII.1961, F. M. Oliveira, Coleção Campos Seabra, 1 espécime (MNRJ); IX.1961, F. M. Oliveira, 1 espécime (MZSP). Itacuruça, sem data, J. C. M. Carvalho, 3 espécimes (MNRJ). Itaguay, Km 47, Estrada Rio-São Paulo, 25.IX.1959, A. Peracchi leg., 2 espécimes (MNRJ). Itatiaia, Inst. Biol. Ent. Agrícola, IX.1929, Dário Mendes, 1 espécime; X.1952, 2 espécimes, X.1962, Dirings leg., 1 espécime (MZSP); 04.IX.1962, n. 1324, J. Halik leg., Halik, 1962 det., 4 espécimes; 03.II.1963, J. Halik leg., 2 espécimes (MZSP); 700 m., 14.XI.1927, 1 espécime; 27.VII.1930, 1 espécime; 03.I.1933, 1 espécime; 2.VII.1933, 1 espécime; 14.XI.1933, J. F. Zikan, 1 espécime. Japeri. 20.II.1953, J. Figueiredo, 1 espécime; X.1967, Dirings col., 1 espécime (MNRJ). Maromba 1200 m., 07.I.1954, C. A

C. Seabra, L. C. M. Alvarenga, W. Zikan leg., 1 espécime; 12.I.1944, J. F. Zikan, 1 espécime (INPA); Muri, 29. I.1952, V. Wittmes. G. H. Dieke, 1965 coleção, 1 espécime (USNM); Nova Friburgo, Mury, 131.I.1965, Gred. \& Guimarães leg. 1 espécime; XI.2004, 1 espécime; 22.VII.2006, 1 espécime, 14-19.VII.2007, 1 espécime, P. Grossi leg. (DZUP); Estrada Rio-São Paulo, Km 47, 27.X.1951, 1 espécime; IX.1953, W. Zikan, 2 espécimes (MZSP). Seropédica, 25.IX.2006, E. L. Aguiar-Menezes leg., 2 espécimes; VII.2007, H. Y. S. Quintino leg., 1 exemplar (DZUP). São Paulo. Barueri, 5.IX. 1954, 1 espécime; 9.X.1954, 1 espécime; 10.I.1955, n. 4733, 2 espécimes; 14. X. 1955, n. 6099, 1 espécime; 30.X.1955, 1 espécime; 7. XII.1955, n. 7731, K. Lenko leg., Coleção Campos Seabra, 6 espécimes (MNRJ); XII.1965, 2 espécimes; I.1966, 2 espécimes; XII.1966, 1 espécime; 09.II.1967, K.
Lenko leg., 1 espécime (DZUP). Campinas, sem data, F. C. Camargo, G. H. Dieke, 1965 det., 2 espécimes (USNM); sem data, n. 8085, F. C. C. leg., 5 espécimes (DZUP); sem data, F.C.C. leg., 3 espécimes (2 MNRJ e 1 IBSP); IV.1937, F. Camargo, 4 espécimes (IBSP). Diadema, 12.II.1961, Reichardt leg., 2 espécimes; 25.II.1961, Reichardt \& Werner,1 espécime; 16.II.1962, 3660, W. B. leg. Halik, 1962 det., 1 espécime (MZSP); Amparo, Fazenda Santa Maria, 27.XI.1942, sem coletor, 1 espécime. Itú, Fazenda Pau d'alho, I.1959, 3 espécimes; II.1959, 2 espécimes; 27.XII.1959, U. Martins leg., 5 espécimes; 1215. XI.1960, M. A . Vulcano, 1 espécime; XII.1960, U. Martins, 1 espécime; 9-10.IX.1961, L. R. Silva, 3 espécimes; II.1963, F. Werner, U. Martins, 1 espécime; 25-29.X.1965, Martins \& Biasi, 1 espécime; VII.1956, U. Martins, 1 espécime; 27.XII.1958, U. Martins, 1 espécime (MZSP). Mairiporã, sem data, C. Costa leg., 1 espécime (MZSP); Osasco, 13.IV. 1938, F. Lane leg., F. C. Camargo, 1939 det., 1 espécime; XI.1956, Keller leg., 1 espécime (MZSP). Pindamonhangaba, Eugênio Lefévre, 28.X.1962, Exp. Dep. Zool. 2 espécimes (DZUP). Piracicaba (ESALQ - horticultura), 13. V. 1998, Paulo Mendes, 1 espécime (ESALQ). São Paulo, Cantareira, VII.1937, E. Schw. Leg., 2 espécimes; 17. II. 1960, n 3595, J. Halik leg., F. Halik det. 1960, 2 espécimes (MZSP). Jabaquara, II.1937, n. 1571, 1 espécime; I. 1938, n. 1373, 1 espécime; IV.1938, 2942, J. Guerin leg., 1 espécime; III.1939, 2888, J. Guerin leg., F. C. Camargo, 1939 det., 1 espécime (IBSP); Vila Amália, 21.IV.1960, nr. 122, 601 a 604, F. Halik leg., F. Halik, 1960 det., 5 espécimes (MZSP); X.1938, Colégio Claretiano, n.4244, 1 espécime (MNCI). São Roque, 1.IV.1937, 122/FCC-260, 1 espécime; sem data, 1 espécime (MNRJ). 

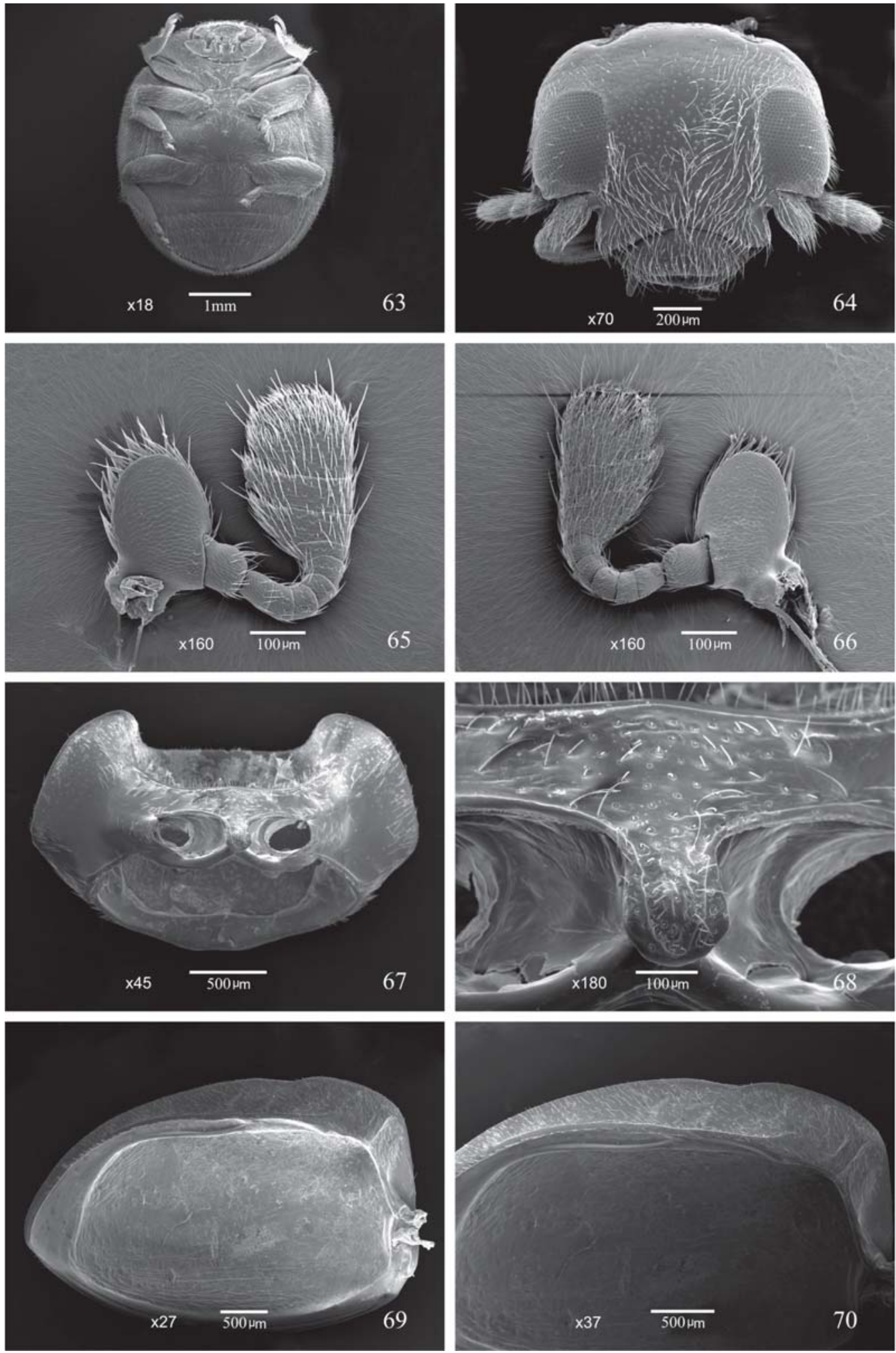

Figs. 63-70. Exoplectra miniata (Germar, 1824). 63, vista ventral; 64, cabeça, vista dorsal; antena: 65, vista ventral; 66, vista dorsal; 67, protórax; 68, processo prosternal; 69, élitro, vista ventral; 70, epipleura.

Tupan, 21’55 5028 500m., V.1947, F. Plaumann, 2 espécimes (DZUP). Paraná. Curitiba, Ponte Ahú, VII.1936, F. C. Camargo, 1939 det., 1 espécime (MNRJ); X.1940, Coll. Claretiano, n. 4247, 1 espécime (MNCI); R. Korschefsky, 1939. 922/ FCC-1311, 1 espécime (DZUP).
Discussão taxonômica. Exoplectra miniata diferencia-se facilmente das demais espécies do gênero pelo tegumento avermelhado, com máculas circulares pretas, duas no pronoto e cinco em cada élitro. Assemelha-se com E. heydeni pela 
forma do corpo e pubescência branca, presença de linha oblíqua e pelo padrão da genitália do macho, porém diferenciase pela presença de máculas, dente da tíbia obtuso e pela genitália da fêmea que apresenta o ramo e nódulo curtos.

\section{Exoplectra santaremae Crotch, 1874}

(Figs. 43, 60)

Exoplectra santaremae Crotch, 1874: 286; Korschefsky, 1932: 228; Blackwelder, 1945, 451; Gordon, 1987: 34.

Fêmea. Corpo arredondado (Fig. 60), pubescência branca. Tegumento vermelho. Cabeça, peças bucais e antenas castanhas avermelhadas. Pronoto preto com borda láteroapical avermelhada. Élitros avermelhados com três máculas pretas: a primeira em faixa sinuosa, contornando toda a margem externa do élitro, até o ápice, onde se alarga; a segunda, arredondada, abaixo do calo umeral; a terceira, semicircular, no disco elitral, próxima à sutura. A união das máculas do disco forma uma figura circular. Escutelo preto. Coloração ventral do tórax preta. Pernas castanho-escuras, tíbias com dente agudo, formando um espinho. Abdome avermelhado, com linha oblíqua.

Genitália. Coxito subtriangular, alongado, duas vezes mais longo do que largo. Espermateca com ramo alongado e nódulo curto (Fig. 43).

Dimensões (em mm). Comprimento total: 4,58 - 5,00. Largura: $4,00-4,25$.

\section{Distribuição geográfica. Brasil (Pará).}

Material-tipo. O lectótipo ㅇ recebido do Departament of Zoology, University of Cambridge, Cambridge, Inglaterra, foi estudado e possui as seguintes etiquetas: uma azul: [TYPE] e três brancas [TYPE, santaremae, Bates], [LECTOTYPE, Exoplectra santaremae Crotch 1874, Gordon 1987] e [University Museum of Zoology, CAMBRIDGE].

Material examinado. BRASIL. Sem localidade, sem data, 1 espécime lectótipo, Bates leg. (DZUC). Pará. Mocajuba, Mangabeira, X. 1952, Orlando Rego, Coleção Campos Seabra, 1 espécime (MNRJ).

Discussão taxonômica. Exoplectra santaremae apresenta um padrão característico de máculas em cada élitro que permite diferenciá-la das demais espécies com facilidade. Assemelhase à E. amazonica pelo padrão de coloração, mas apresenta além da mácula no disco central, outras máculas pretas contornando os élitros e uma em cada um dos calos umerais. Além disso, possui diferença na forma dos coxitos na genitália da fêmea.

\section{Exoplectra columba sp. nov.}

(Figs. 44 - 46, 61)

Macho. Corpo oval (Fig. 61), pubescência amarelada. Tegumento preto metálico, com reflexo verde. Cabeça e peças bucais enegrecidas, antenas castanhas. Pronoto com borda látero-apical translúcida. Coloração ventral preta. Tíbias com dente obtuso, tarsos castanhos. Abdome com o primeiro segmento e a metade do segundo pretos e os demais avermelhados, com linha oblíqua.

Genitália. Parâmeros com cerdas muito longas, duas vezes maiores que o lobo médio, este mamiliforme (Fig. 44). Sifão longo com cápsula curta e ápice arredondado (Fig. 45).

Fêmea. Semelhante ao macho.

Genitália. Coxitos subtriangulares duas vezes mais longos que largos. Espermateca com ramo e nódulo curtos (Fig. 46).

Dimensões (em mm). Comprimento total: 4,58 - 5,00. Largura: $4,00-4,42$.

Distribuição geográfica. Brasil (Mato Grosso, Goiás, Minas Gerais, Rio de Janeiro, São Paulo, Paraná, Santa Catarina).

Material-tipo. Holótipo ơ depositado na Coleção de Entomologia Pe. J. S. Moure, Departamento de Zoologia, Universidade Federal do Paraná, Curitiba, com as seguintes etiquetas: uma branca: [Depto. Zool, UF - PARANÁ]; [Fenix - Paraná, 03-X-1985, Exp. Dep. Zoo (Concitec)]. Os dados dos parátipos, assim como as coleções onde estão depositados são indicados no material examinado.

Material examinado. BRASIL. Mato Grosso. Chapada dos Guimarães, XI.1963, 2 espécimes parátipos (MZSP). Goiás. Corumbá de Goiás, 31.I - 03.II.1962, J. Bechyné leg. 1 espécime parátipo (MZSP). Dianópolis, 11 - 14.I.1962, 3 espécimes. Goiânia, 26.I.1962, 1 espécime (MZSP). Jataí, Fazenda Aceiro, X.1962, Exp. Dep. Zool.; 1 espécime (MZSP). Minas Gerais. Serra do Caraça, 27.XI - 05.XII.1972, Exp. Mus. Zool., 1 espécime (MZSP). Varginha, IX.1961, M. Alvarenga, 1 espécime. Rio de Janeiro. Rio de Janeiro, Guanabara, Represa Rio Grande, 20.X.1967, F. Oliveira leg.,1 espécime. São Paulo. Barueri, XII.1965, 1 espécime; I.1966, K. Lenko, 1 exemplar (MZSP). Paraná. Fênix, 30.IX.1985, 1 espécime parátipo; 01.X.1985, 1 espécime parátipo; 02.X.1985, Exp. Dep. Zoo. Concitec, 1 espécime parátipo; 03.IX.1985, 1 espécime; 03.X.1985, 2 espécimes, 1 holótipo (DZUP). Foz do Iguaçu, 10.XII.1966, Exp. Dep. Zoo.1 espécime (DZUP). Guarapuava, 01.X.1986, 1 espécime parátipo; 02.X.1986, 1 espécime parátipo, Profaupar (DZUP). Santa Catarina. Nova Teutônia, VIII.1939, n. 15764, J. Guerin, 1 espécime parátipo (IBSP); XI. 1951, 1 espécime; X.1961, 1 espécime; X.1965, 1 espécime; XI.1965, 4 espécimes; IV.1966, 8 espécimes; X.1966, 1 espécime; IX.1966, 1 espécime; XI.1966, 4 espécimes; VI.1968, 1 espécime; I.1974, 8 espécimes; II.1974, 8 espécimes; X.1974, 7 espécimes; XII.1974, 1 espécime; X.1980, 2 espécimes; XI.1980, 4 espécimes; XII.1980, 3 espécimes; III.1981, 1 espécime, Fritz Plaumann (DZUP). Rio Grande do Sul. Tenente Portela, 17.I.1985, A. Lise leg., 1 espécime parátipo (FZRG).

Discussão taxonômica. E. columba sp.nov. assemelha-se a E. calcarata pela coloração preta metálica, porém, difere pela pubescência amarelada, corpo ovalado, tamanho menor e padrão de genitália da fêmea, com coxitos menores e subtriangulares.

Etimologia. Nome relativo à coloração preta metálica com reflexo verde como nas pombas.

\section{Exoplectra bimaculata sp. nov.} (Figs. 47 - 48, 62)

Macho. Corpo arredondado (Fig. 62), pubescência amarelada, tegumento vermelho. Cabeça preta, peças bucais e antenas castanhas. Pronoto preto com borda látero-anterior 

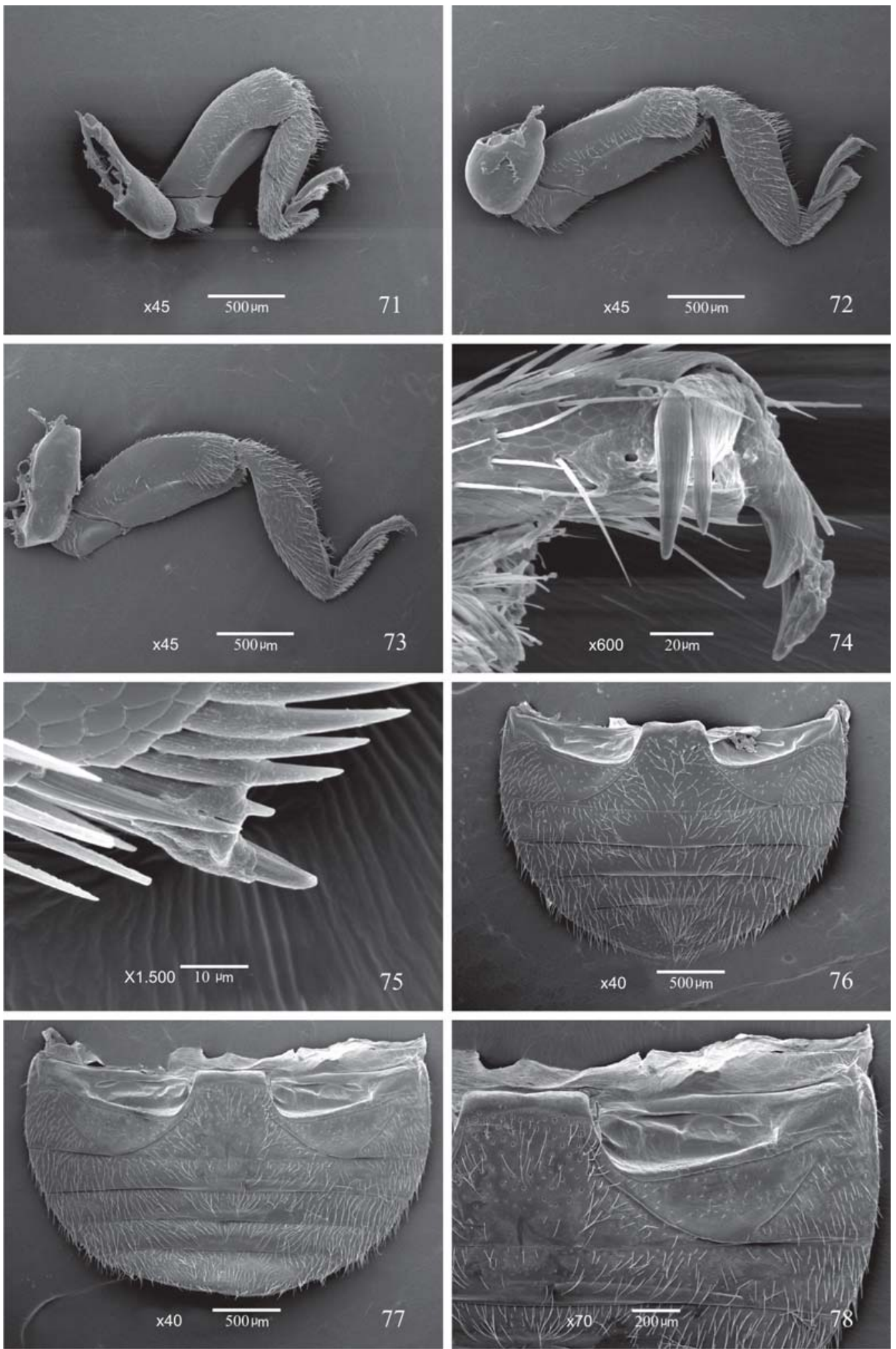

Figs. 71-78. Exoplectra miniata (Germar, 1824). 71, perna anterior; 72, perna média; 73, perna posterior; 74, perna anterior, garra; 75, perna posterior, esporão tibial; abdome: 76, fêmea; 77, macho; 78, linha oblíqua.

castanha contornando finamente a margem apical e estendendo-se lateralmente. Escutelo preto. Élitros avermelhados, cada um com duas máculas circulares: a primeira no disco elitral, próxima da sutura, a segunda junto à margem externa em sua metade. Epipleura com contorno externo preto. Meso e metaesterno pretos com as laterais avermelhadas. 
Pernas castanhas. Tíbias com dente lateral agudo em forma de espinho. Abdome avermelhado com o primeiro segmento enegrecido, com linha oblíqua.

Genitália. Parâmeros com cerdas longas, poucos maiores que o lobo médio este afilado gradativamente (Fig. 47). Sifão com cápsula curta e ápice com bolsa prepucial pouco desenvolvida (Fig. 48).

Dimensões (em mm). Comprimento total: 4,25. Largura: 3,83.

\section{Distribuição geográfica. Brasil (Amazonas).}

Material-tipo. Holótipo o depositado no Museu de Zoologia da Universidade de São Paulo, com as seguintes etiquetas brancas: [BRASIL, Itacoatiara, AMAZONAS, Col. Dirings, JAN. 1965].

Material examinado. O mesmo relacionado no material-tipo.

Discussão taxonômica. Exoplectra bimaculata sp. nov. assemelha-se à E. amazonica pela forma do corpo e coloração do pronoto, porém diferencia-se pela presença de duas máculas em cada élitro, ausência de linha oblíqua e pelo padrão da genitália com cerdas dos parâmeros finas e forma do ápice e da cápsula sifonal.

Etimologia. Nome relativo às duas máculas pretas presentes em cada um dos élitros.

Agradecimentos. Ao Conselho Nacional de Desenvolvimento Científico e Tecnológico ( $\mathrm{CNPq}$ ) pelas bolsas concedidas. Aos pesquisadores responsáveis pelas coleções que forneceram material para estudo, Drs. Willian A. Forster (DZUC); Miguel A. Monné (MNRJ); Sônia Casari (MZSP); Manfred Uhlig (MNHUB); Marcia Arzua (MNCI); Augusto A. Loureiro (INPA); Sérgio Ide (IBSP); Natalia Vandenberg (USNM); Maria Helena Galileo (FZRG), David H. Kavanaugh (CAS); Ole Martin (ZMUC). Ao Dr. Robert Gordon e aos dois revisores anônimos pelas sugestões.

\section{REFERÊNCIAS}

Almeida, L. M. 1987. Estudo de 17 espécies do gênero Psyllobora Chevrolat, 1837 (Coleoptera, Coccinellidae). Acta Biológica Paranaense 14: 47-112.

Almeida, L. M. \& J. Milléo. 2000. Revision of The Genus Hinda Mulsant (Coleoptera, Coccinellidae, Hyperaspinae, Brachiacanthadini). Coleopterists Bulletin 54: 68-87.

Bartoszeck, A. B. 1980. Ocorrência de Toxoptera citricidus (Aphididae) e seus inimigos naturais em Imperatriz, MA, Brasil. Dusenia 12: $8-13$.

Blackwelder, R. E. 1945. Checklist of the Coleopterous Insects of Mexico, Central America, the West Indies, and South America. Bulletin United States National Museum 185: 343-550.

Berg, F. C. C. 1874. Notícias criticas sobre algunas publicationes entomológicas. Boletin de la Academia Nacional de Ciências 1: 274-293.

Brèthes, J. 1925. Coccinellides du Britsh Museum, Nouveaux Coléoptères Sudméricains. Nunquam Otiosus IV: 1-16.

Bruch, C. 1914. Catálago Sistemático de los Coleópteros de la República Argentina. Universidad Nacional de La Plata IX: 385-389.
Casey, T. L. 1908. Notes on the Coccinellidae. The Canadia Entomologist 40-41: 393-421.

Chapuis, F. 1876. Histoire naturelle des Insectes. Genera des Coléoptères, Paris, 12: 1-424.

Chazeau, J.; H. Fürsch \& H. Sasaji. 1989. Taxonomy of Coccinellids. Coccinella 1: 6-8.

Chevrolat, L. A. 1844. In d' Orbigny, Dictionaire Universel d' Histoire Naturelle 5: 545.

Contreras, G. 1951. Coccinelídeos Colombianos. Revista de la Academia Colombiana de Ciencias Exactas, Fisicas y Naturales 8: 243-244.

Crotch, G. R. 1874. A revision of the Coleopterous Family Coccinellidae. London, $311 \mathrm{p}$.

Dejean, P. F. M. A. 1837. Catalogues des Coléoptères de la Collection de M. le comte Dejean 5. Paris, 503.

Drea, J. J. \& R. D. Gordon. 1990. Predators. In: The Armored Scale Insects, Their Biology, Natural Enemies and Control B: 1940 .

Fabricius, J. C. 1801. Systema Eleutheratorum. 1. Kiliae

Fürsch, H. 1990. Taxonomy of Coccinellids. Coccinella 2: 4-18.

Gemminger, M. \& B. Harold. 1876 Catalogus Coleopterorum hucusque descriptorum synonymicus et systematicus, Monachii 12: 3740-3818.

Germar, E. F. 1824. Insectorum species novae aut minus cognitae, descriptionibus illustratae, $624 \mathrm{pp}$.

Gordon, R. D. 1985. The Coccinellidae (Coleoptera) of America North of Mexico. Journal of the New York Entomological Society 93: $668-671$

Gordon, R. D. 1987. A Catalogue of the Crotch Collection of Coccinellidae (Coleoptera). Occasional Papers on Systematic Entomology 3: 34 .

Gordon, R. D. 1994. South American Coccinelidae (Coleoptera) Parte III: Definition of Exoplectrinae Crotch, Azyinae, Mulsant and Coccidulinae Crotch; A Taxonomic Revision of Coccidulini. Revista Brasileira de Entomologia 38: 681-775.

Gorhan, H. S. 1895. Biologia Centrali-Americana, Insecta, Coleoptera, Coccinellidae. VII: 209-216.

Horn, W. \& I. Kahle. 1935-1937. Über entomologische Sammlungen, Entomologen \& Entomo-Museologie. 533 p. + XXXVIII Tab.

Korschefsky, R. 1932. Coccinellidae I. In Coleopterorum Catalogus. Part 120. Berlin, W. Junk, p. 225-659.

Linnaeus, C. 1758. Systema naturae - Regnum Animals. 10 ed. Stockholm. 826 pp.

Marinoni, R. C. \& L. M. Almeida. 1983. Sobre a venação alar em Coccinellidae e Cerambycidae (Coleoptera). Revista Brasileira de Entomologia 27: 267-275.

Mulsant, M. E. 1850. Species des Coléoptères trimères sécuripalpes. Annales des Sciences Physique et Naturelles d'Agriculture et d'Industrie 2: 1-1104.

Nunenmacher, F.W. 1912. Studies amongst the Coccinellidae, 3. Psyche 19: $149-151$

Schönherr, C. J. 1808. Synonymia insectorum, order: Versuch einer Synonymie aller bisher bekannten Insecten; nach Fabricii Systema Eleutheratorum geordnet. Stockholm 1: 1293.

Sicard, A. 1912. Descriptions d'espèces et variétés nouvelles de Coccinellides de la collection du Deutsches Entomologisches Museum de Berlin-Dahlem. Archiv Naturgische 78: 129-138.

Weise, J. 1895. Neue Coccinelliden. Annales de la Société Entomologique de Belgique 39: 120-146.

Weise, J. 1922. Coleoptera e collectione Brachiana. Anales de la Sociedad Científica Argentina 94: 30-40. 